\title{
Effects of Physical Exercise on Inflammatory Markers of Atherosclerosis
}

\author{
A. Pinto ${ }^{\#}$ D. Di Raimondo ${ }^{\#, *}$, A. Tuttolomondo, C. Buttà, G. Milio and G. Licata
}

U.O. di Medicina Vascolare - U.O. di Medicina Interna e Cardioangiologia, Dipartimento Biomedico di Medicina Interna e Specialistica, Università degli Studi di Palermo, Italy

\begin{abstract}
It is well established that physically fit individuals have a reduced risk of developing CVD (cardiovascular disease) and other age-related chronic disorders. Regular exercise is an established therapeutic intervention with an enormous range of benefits. Chronic low-grade systemic inflammation may be involved in atherosclerosis, diabetes and in pathogenesis of several chronic pathological conditions; recent findings confirm that physical activity induces an increase in the systemic levels of a number of cytokines and chemokines with anti-inflammatory properties. The possibility that regular physical exercise exerts anti-inflammation activity, being the interaction between contracting muscle and the other tissues and the circulating cells mediated through signals transmitted by "myokines" produced with muscle contractions. To date the list of myokines includes IL-6, IL-8, and IL-15. During muscle contractions are also released IL1 receptor antagonis and sTNF-R, molecules that contribute to provide anti-inflammatory actions.

Nevertheless discrepancies, analysis of available researches seem to confirm the efficacy of regular physical training as a nonpharmacological therapy having target chronic low-grade inflammation. Given this, physical exercise could be considerate a useful weapon against local vascular and systemic inflammation in atherosclerosis. Several mechanisms explain the positive effect of chronic exercise, nevertheless, these mechanisms do not fully enlighten all pathways by which exercise can decrease inflammation and endothelial dysfunction, and hence modulate the progression of the underlying disease progress.
\end{abstract}

Keywords: Physical exercise, atherosclerosis, inflammation, C-reactive protein, interleukin-6.

\section{INTRODUCTION}

\section{Atherosclerosis: an Inflammatory Disease}

Since in 1999 Russell Ross published his review [1], atherosclerosis has been considered an inflammatory disease and several studies have been performed on this matter. Pathophysiology of atherosclerosis is mainly characterized by the accumulation of lipids and fibrous elements in the large arteries, but this "classical" view of the pathophysiology of atherosclerosis is rapidly changing. The link between lipids and atherosclerosis dominated our thinking until the 1970s [2]. The emerging knowledge of vascular biology led to a focus on growth factors and the proliferation of smooth muscle cells in the 1970s and 1980s [2]. Over the past decade, however, there has been much focus on the role of inflammation in the pathogenesis of atherosclerosis [3,4]. Furthermore, inflammation has been suggested to be a key factor in several other chronic diseases such as insulin resistance [5], colorectal cancer [6], stroke [7], chronic obstructive pulmonary disease (COPD) [8] and Alzheimer's disease [9].

The analysis of the relationship among atherosclerosis and inflammation is not the topic of this review, being widely discussed elsewhere in this special issue, but should be underlined that it has been recognized that pleiotropic cytokines are not only important signals in immune function, as they also represent important regulators of endocrine systems, the metabolism, the coagulation system, and the brain function. In addition, it has been discovered recently that circulating levels of cytokines in vivo are affected significantly by contributions of cells outside the immune system such as adipose tissue, skeletal muscle, and endothelial cells in healthy humans; e.g., $30 \%$ of interleukin (IL)-6 in plasma is derived from fat tissue [10]. The concept of regulatory adipokines has developed together with the discovery of fat tissue as an important endocrine organ, producing and secreting classical cytokines including tumor

*Address correspondence to this author at the U.O.C. Medicina Vascolare, Dipartimento Biomedico di Medicina Interna e Specialistica, Università degli Studi di Palermo, Piazza delle Cliniche ${ }^{\circ}$ 2, 90127 Palermo, Italy; Tel: 00390916552102; Fax: 00390916552285 ;

E-mail: domenico.diraimondo@unipa.it

"The two authors equally contributed to the work. necrosis factor (TNF)- $\alpha$, IL- 6 , IL-18, as well as a wide range of other new peptides [11]. Moreover, at the millennium, it was demonstrated that working skeletal muscles produce and also release cytokines to the circulation [12]. Considering that skeletal muscle is the largest organ in the body, the perspective of this finding is revolutionary, and it provides a molecular explanation about a molecular level by which we may understand how exercise mediates some of the health beneficial effects in relation to chronic disorders associated with systemic low-level inflammation.

\section{Chronic Systemic Low-level Inflammation}

Chronic Systemic Low-level Inflammation is defined as modest (2-4-fold) elevations in circulating levels of pro-inflammatory and anti-inflammatory cytokines, natural occurring cytokine antagonists, and acute-phase proteins, as well as minor increases in counts of neutrophils and natural killer cells [13]. Although these increases are far from levels observed during acute, severe infections, systemic low-level inflammation is strongly associated with increasing age, lifestyle factors such as smoking, obesity, and dietary patterns, together with increased risk of CVD, COPD, cognitive decline, and wasting/cachexia (loss of skeletal muscle cells) [14,15]. Several reports investigating various markers of inflammation in different population groups have confirmed an association between lowgrade systemic inflammation on one hand and the metabolic syndrome, Type 2 diabetes, and atherosclerosis on the other [16-18]. Moreover, systemic low-level inflammation is a strong, consistent, and independent predictor of all-cause mortality and CVD-cause mortality in elderly populations [19].

Nevertheless, in the latest years a great debate tried to address the issue if the inflammatory variables are causal related to atherosclerosis or if systemic low-grade inflammation is a spillover of the disctrectual process; recent evidence suggests they really may play a key role in the pathogenesis of CVD and other chronic diseases [20]. Establish the separate effects of the different cytokines and of the other actors of the inflammatory process in atherosclerosis is very hard, because of the fact that circulating levels of inflammatory mediators are often strongly correlated with each other as a result of their tight, regulated production and, finally because inflammatory mediators are correlated with other risk factors in 
chronic morbidity, including levels of fibrinogen, albumin, cholesterol, arterial blood pressure, and body mass index (BMI), among others giving the mission of scientists extremely hard.

\section{Health Benefit of Physical Activity}

It is well established that physically fit individuals have a reduced risk of developing CVD (cardiovascular disease) and other age-related chronic disorders [21]. Regular exercise is an established therapeutic intervention with an enormous range of benefits, including protection against atherosclerosis, colon cancer, and breast cancer [21], ischemic heart disease [22], heart failure [23], Type 2 diabetes [24], and chronic obstructive pulmonary disease [25]. Many are the known mechanism through physical training exerts its beneficial efficacy: correction of the main traditional cardiovascular risk factors, enhancement of muscular exercise tolerance and improvement of physical fitness, enhancement of myocardial and peripheral perfusion, augmented well-being of the individual. But many others mechanisms responsible for the protective effects of exercise remains to date unexplained or not completely clear. The available data provide sure confirmation that usual exercise training reduces morbidity and mortality in atherosclerotic patients [26-29].

Given that chronic low-grade systemic inflammation may be involved in atherosclerosis, diabetes and in pathogenesis of several chronic pathological conditions [4-9] and assumed the recent finding that physical activity induces an increase in the systemic levels of a number of cytokines and chemokines with anti-inflammatory properties, in this review we discuss the possibility that regular physical exercise exerts anti-inflammation activity, being the interaction between contracting muscle and the other tissues and the circulating cells mediated through signals transmitted by "myokines" produced with muscle contractions, and thereby protects against chronic medical disorders associated with low-grade systemic inflammation such as atherosclerosis. We discuss also in this review the effects of regular exercise on established markers and mediators of inflammation of atherosclerosis and the impact that different types and intensities of exercise may have on inflammatory background of atherosclerotic damage and on vascular outcome of patients.

\section{PART I - INFLAMMATORY MARKERS OF ATHERO- SCLEROTIC DISEASE}

Atherosclerosis is widely recognized as a chronic inflammatory disorder that results from the interactions between modified lipoproteins and various components of the immune system, including monocyte-derived macrophages, T-lymphocytes and a variety of cytokines secreted by these and other cells in the artery wall [30].

Many factors contribute to the development of vascular inflammation of atherosclerosis during several decades of progression of the parietal lesions. One of the main concerns the oxidation of the protein and lipid components of LDL (low-density lipoprotein) particles [30]. Elevated LDL is a well-known CVD risk factor and can drive the development of atherosclerosis even in the absence of other known risk factors. LDL is normally permeant to the arterial endothelium [31], but when levels are elevated it can accumulate in the subendothelial (intimal) space, where it becomes oxidized by enzymes such as myeloperoxidase, 15-LO (lipoxygenase) and iNOS (inducible nitric oxide synthase) [30]. Oxidized LDL (oxLDL), retained in the intima and associated with the extracellular matrix proteins is believed to be able to promote local inflammation, contributing to initiate many of the local pro-inflammatory effects associated to the development of atherosclerotic plaques [32]. The inflammation initiated by ox-LDL is mediated largely by the local production of pro-inflammatory cytokines in the artery wall. Cytochines, locally exert their pro-inflammatory effects promoting endothelial cell dysfunction; facilitating influx into the arterial wall of lynphocites, neutrophils monocytes; regulating macro- phage and T-cell activation and proliferation, altering SMC (smooth muscle cell) phenotype; inducing apoptosis, and finally promoting plaque rupture and thrombosis [33-35].

Atherosclerotic damage is not only characterized by a local inflammation, being also demonstrated a frame of systemic inflammation. Probably systemic inflammation is not expression of vascular damage, or a simple marker of local pathology, but a pathogenetic element able to contribute to the systemic development of atherosclerosis $[4,5]$.

Inflammatory mechanism plays a central role in mediating all phases of atherosclerosis, from initial recruitment of circulating leucocytes to the arterial wall to eventual rupture of unstable plaque. Systemic inflammation in atherosclerosis, such as in several conditions in which is needed a response to a infection or to a tissue injury, involves hepatic production of proteins, called "acute-phase proteins", such as CRP. Their circulating levels are currently used in order to assess entity of inflammatory response and, consecuently, severity of injury. The main cytochines involved in this inflammatory cascade are: TNF- $\alpha$, IL- $1 \beta$, IL-6, IL-1 receptor antagonist (IL-1 ra), and soluble TNF- $\alpha$ receptors (sTNFR). IL-1 ra inhibits IL-1 signal transduction and sTNF-R represents the naturally occurring inhibitors of TNF- $\alpha[36]$.

\section{Chronic Low-grade Systemic Inflammation in Atherosclerosis}

In response to an acute infection or trauma, the cytokines and cytokine inhibitors may increase severalfold and decrease when the infection or trauma is healed. Far from this, what we observe in association to atherosclerotic disease is a "chronic low-grade systemic inflammation". Chronic low-grade systemic inflammation, as defined before [13], accompanies aging, lifestyle factor such as smoking, obesity and dietary patterns as well as some chronic medical disorders increased risk of cardiovascular disease, type 2 diabetes cognitive decline, and wasting/ cachexia (loss of skeletal muscle cells) more common in the last part of life [37-39]. During aging, increased plasma levels of sTNF-R [40], TNF- $\alpha$, IL-6, IL1 ra and CRP [41] have been demonstrated. These cytokines work in a network, and their levels are found to intercorrelate, e.g., plasma levels of TNF- $\alpha$ were positively correlated with IL-6, sTNF-R, and CRP in centenarians [38]. However, although a linear relationship was found for TNF- $\alpha$ and IL-6, high levels of TNF- $\alpha$, but not IL-6, were associated with dementia and atherosclerosis [40,42]. Increased levels of both TNF- $\alpha$ and IL- 6 have been observed in obese individuals, in smokers, and in patients with Type 2 diabetes mellitus [43], Moreover, systemic low-grade inflammation is a strong, consistent, and independent predictor of all-cause mortality and CVD-cause mortality in elderly populations [44]. Furthermore, plasma concentrations of IL- 6 and TNF- $\alpha$ have been shown to predict the risk of myocardial infarction in several studies [45], and it was shown that the CRP level is a stronger predictor of cardiovascular events than the low-density lipoprotein cholesterol level and that CRP adds prognostic information to that conveyed by the Framingham risk score [46].

Presence of a state of chronic low-grade systemic inflammation in atherosclerotic patient is confirmed by finding of persistence elevation of numerous inflammatory variables, including the cytokines TNF- $\alpha$, IL-6, IL-1 $\beta$, IL-2, IL-7, IL-8, IL-10, IL-18, IL-1ra, sTNF-R, and other related to acute phase response such as CRP, Pselectin, soluble intercellular adhesion molecule-1 (ICAM-1), sCD40L (solubleCD40 ligand) and M-CSF (macrophage colonystimulating factor) [42]. Despite the fact that serum levels of this inflammation-related substances are much smaller than those seen in acute infection, this pattern suggest a clear involvment of inflammation in atherosclerosis. Determining whether they are a cause or a consequence of atherosclerosis remains a challenge like identify the contribution that individual cytokines and other inflammatory variables make to the development of atherosclerosis. This latest point is really difficult to ascertain due to the interactions 
and redundancy between the numerous pro- and anti-inflammatory cytokines that define chronic inflammation. Furthermore, most secreted cytokines are rapidly cleared by surrounding cells or inactivated by soluble inhibitors, thus measuring their circulating levels does not necessarily reflect their biological activity in tissues.

Finally, cytokines serum levels changes and could related to several genetic polymorphisms. Single Nuclear Polymorfisms (SNPs) of several cytokines genes have been demonstrated, and their biological action and clinical significance is actually under evaluation by several groups. Regarding the matter of the present review, polymorphisms of Il- 6 and TNF- $\alpha$ genes are the more relevant. IL-6 is largely regulated at the level of expression, because of the rapid plasma clearance of this cytokine. Four polymorphisms exist in the IL-6 promoter, although most population-based studies focus on the G-174-C, where the C allele shows lower IL-6 expression than the G allele [47]. The G-174-C genotype is a disease "risk genotype" associated with cardiovascular disease and all-cause mortality in old humans, as well as insulin resistance and low energy expenditure [48]. Compared with the G-308G genotype, the $308 \mathrm{~A}$ allele of the TNF- $\alpha$ gene has been shown to increase transcription twofold and, therefore, TNF- $\alpha$ concentration [49]. Subjects with risk genotypes for both TNF- $\alpha$ (AA) and IL-6 (CC) have the highest incidence of diabetes [50], favouring the theory that high levels of TNF- $\alpha$ and low production of IL- 6 are determining factors in the metabolic syndrome.

Given that TNF- $\alpha$ mainly works locally, TNF- $\alpha$ transcription may not always be reflected in enhanced systemic levels of TNF- $\alpha$. Rather, TNF- $\alpha$ could be hypothesized to stimulate IL- 6 production and consequently IL-1ra and CRP [51].

For all these and also other reasons, as we can see as follows, the mechanisms by which inflammatory cytokines affect atherogenesis are still poorly understood. Although in many studies, the effects of absence of increased levels of inflammatory cytokines on atherosclerosis were investigated, the exact inflammatory pathways are still unclear.

A thorough examination of the role of each of these cytokines in atherosclerosis is beyond the scope of this review, but a brief analysis of the main pro-inflammatory and anti-inflammatory cytokines related to promotion or control of atherosclerosis appears useful. Thereby, in the following part we will try to summarize the main characteristics of the cytokines and of the acute phase proteins involved in the acute and chronic systemic response to exercise.

Cytokines represent a model on a molecular level, by which we can explain some of the interconnection amongst markers of inflammation, coagulation/fibrinolysis, glucose metabolism, lipid metabolism, the renin-angiotensin system, the hypothalamicpituitary axis, and others associated with systemic low-level inflammation in atherosclerosis, and by analysing the variations of which we try to explain the anti-inflammatory effect of exercise therapy.

\section{Tumor Necrosis Factor- $\alpha$ (TNF- $\alpha)$}

TNF- $\boldsymbol{\alpha}$ is multifunctional, and one of the most important proinflammatory and immune modulatory cytokines [52]. TNF- $\alpha$ mediates mainly local inflammatory responses, the systemic acutephase response and is thought to play a central role in the development of CVD, Type 2 diabetes and the metabolic syndrome [53]. Nevertheless elevated levels of TNF- $\alpha$ protein is not always detected in serum patients during systemic low-grade inflammation, Bruunsgaard [53] hypothesize that local (vascular, in case of atherosclerosis) production of TNF- $\alpha$ may stimulate production of IL-6 and subsequent mediators in the inflammatory cascade; in this view, increases in IL-6, IL-8, C reactive protein (CRP), IL-1Ra, sTNFRs, IL-10, and inflammatory cells, among others, would reflect on-going TNF- $\alpha$ production, and then systemic biomarkers of low-grade inflammation found in atherosclerotic patient may repre- sent a response to or a spillover from local vascular inflammation TNF- $\alpha$ mediated second-affecting the function in other organs and tissues. Probably is not completely correct to point to TNF- $\alpha$ as the agent solely responsible in inflammatory disorders (as Bruunsgaard herself affirms later in her review), however, In terms of CVD, elevated circulating levels of TNF- $\alpha$ predict risk of myocardial infarction (MI) [45], the severity of PAD (peripheral arterial disease) [40] and the extent of carotid artery atherosclerosis in healthy middle-aged men [54]. TNF- $\alpha$ is prevalent in atherosclerotic lesions [55] and induces the expression of adhesion molecules such as ICAM-1 (intracellular adhesion molecule-1) and E-selectin [56]. TNF- $\alpha$ as well as IL- 1 also promote low shearstress-induced neointimal hyperplasia [57], a hallmark feature of atherosclerosis and finally it induces endothelial dysfunction [58]. Therefore, it should have a major role in atherogenesis. Surprisingly, no effect was found in the first article studying atherogenesis in a mouse model deficient for TNF- $\alpha$ [59]. Although the experimental conditions weren't optimal to evaluate atherosclerosis progression, results of this study seemed to reveal that such an important cytokine as TNF$\alpha$ is not absolutely crucial for the development of atherosclerosis. Later studies do not confirm these data showing that absence of $\mathrm{TNF}$ in apoE $\mathrm{E}^{-/-}$mice can reduce atherosclerosis [60]. These and other similar studies, indicate that the analysis of the signalling pathways of TNF- $\alpha$, could partially explain the differences observed in biologic effect, infact signalling through the TNF-p55 axis (an element of the NF- $\kappa \mathrm{B}$ system of nuclear transcription factors) may protect against or enhance atherogenesis, maybe depending on the genetic background of the mouse strain used. It is clear that TNF- $\alpha$ signalling is not an obvious pro-atherosclerotic pathway, but the exact mechanisms remain to be elucidated [61].

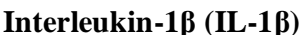

IL-1 $\beta$ is also a proinflammatory cytokine and has been studied in atherosclerosis using either IL-1 $\beta$ - deficient mice or mice lacking the $\mathrm{IL}-1$ receptor. Absence of $\mathrm{IL}-1 \beta$ in apo $\mathrm{E}^{-/-}$mice was shown to reduce atherosclerosis by $30 \%$ [62]. This effect was accompanied by decreased expression of one of the major adhesion molecules in atherosclerosis, VCAM-1, and chemokine MCP-1. In line with these data, absence of IL-1 receptor was shown recently to have strong reducing effects on atherosclerosis development in apoE ${ }^{+/-}$ mice [63]. It should be noted that both TNF- $\alpha$ and IL- 1 are regulated by NF- $\kappa \mathrm{B}$, but they are also activators of the NF- $\kappa \mathrm{B}$ pathway. Hereby, these cytokines may affect atherosclerosis by regulating many other NF- $\mathrm{kB}$ dependent genes and amplify the inflammatory response [61].

\section{Interleukin-6 (IL-6)}

IL-6 is found primarily in the circulation, secreted by numerous cell types, including activated macrophages and lymphocytes, in response to IL- 1 and TNF- $\alpha$. In line with other cytokines, IL-6 is traditionally classified as pro-inflammatory based on the fact that serum levels increase in response to sepsis [64], it stimulates the production of pro-inflammatory cytokines from monocytes and macrophages, and up-regulates CRP production by the liver [65]. There is strong evidence that IL-6 serum concentration increases with age and in 1993, William Ershler, in his article "IL-6: A Cytokine for Gerontologists," indicated IL-6 as one of the main signaling pathways implicated in aging and chronic morbidity [66]. Many studies report that IL-6 plasma levels are increased in patients with unstable angina compared with those with stable angina or healthy subjects and that it could be useful as a prognostic marker of CVD outcome [67], increases the risk of future MI (myocardial infarction) [45] and has been linked to all-cause and CVD mortality [68]. IL-6 also has been hypothesized to promote atherosclerosis directly by enhancing endothelial expression of chemokines and adhesion molecules, increasing endothelial dysfunction and promoting a procoagulant state [69]. 
Studying IL-6 role in atherogenesis in IL-6 deficent mice Elhage et al. [70] surprisingly showed how early lesion formation was not affected by the absence of IL-6. In contrast, when atherosclerosis was examined at 1 year of age, the atherosclerotic lesions were larger in the apo: ${ }^{-/-}$IL-6 - deficient mice compared with controls, making IL-6 an antiatherogenic factor. Interestingly, Xing et al. [71] showed that IL-6 -deficient mice showed increased induction of proinflammatory cytokines in 2 models of local and systemic endotoxic shock. These observations seem to indicate that IL-6 can function as an anti-inflammatory cytokine required for controlling inflammation. Huber et al. [72] showed that administration of recombinant IL-6 aggravates atherosclerosis, but it is not clear whether this is a direct result of IL-6 or merely a reflection of the proatherogenic effects of systemic inflammation that might be induced by IL-6. This is a problem also encountered in similar studies in which proinflammatory substances are administered systemically, making the direct effects on atherosclerosis difficult to interpret. Supposed anti-inflammatory actions of IL-6 include inhibition of the production of TNF- $\alpha$ in response to pro-inflammatory stimuli, such as endotoxin or lipopolysaccaride (LPS) [73], and releasing of sTNFRs (soluble TNF- $\alpha$ receptors) [51], indicating that circulating IL- 6 is involved in the regulation of TNF- $\alpha$ levels. IL-6 also stimulates the production of the anti-inflammatory cytokines IL-1ra (IL-1 receptor antagonist) and IL-10 [51]. In vivo studies appear to support an anti-inflammatory role for IL-6; deficiency in IL-6 has been shown to promote atherosclerosis in both $\mathrm{C} 57 / \mathrm{B} 16$ [74] and ApoE (apolipoprotein E)-deficient (ApoE-/-) mice [75] and had no effect on atherosclerosis in LDLr (LDL-receptor)deficient (LDLr-/-) mice [76]. Perhaps due to these apparent proand anti-inflammatory activities, the role of IL- 6 in atherosclerosis and other inflammatory disorders, such as Type 2 diabetes [51] is controversial, being hypothesized that chronically elevated IL-6 is simply a marker for ongoing TNF- $\alpha$ production during low-grade inflammation and may not contribute directly to the pathogenesis of inflammatory diseases [51,53]. With regard to patients with lowgrade chronic inflammation, as seen, e.g., in patients with CVD or type 2 diabetes, to date there are no published data that allow us to evaluate the direct metabolic effects (pro-inflammatory or antiinflammatory) of modest, but chronic, elevated levels of IL-6 corresponding to the levels seen in these patients. However, blocking IL6 in clinical trials with patients with rheumatoid arthritis, a pathologic condition characterized by highly elevated chronic levels of IL-6, in which this cytokine play a clear pathogenetic role as demonstrated by the fact that blocking IL-6 has beneficial effects on arthritis, leads to enhanced cholesterol and plasma glucose levels, indicating that functional lack of IL-6 may lead to insulin resistance and an atherogenic lipid profile [77]. These clinical findings are in accordance with the finding that IL-6 knockout mice develop lateonset obesity and impaired glucose tolerance [78]. Subjects with risk genotypes for both TNF- $\alpha$ (AA; A shows increased TNF transcription) and IL-6 (CC; C shows decreased transcription) have the highest incidence of diabetes [79], favouring the theory that high levels of TNF- $\alpha$ and low production of IL- 6 are determining factors in the metabolic syndrome [80].

Given the different biological profiles of TNF- $\alpha$ and IL-6 and given that TNF- $\alpha$ may trigger IL- 6 release, one current theory is that adipose tissue-derived TNF- $\alpha$ is actually the "driver" behind the metabolic syndrome and that increased systemic levels of IL-6 reflect locally produced TNF- $\alpha$ [51]. Accordingly, elevated levels of IL-6 might represent a "defense" mechanism against proinflammatory actions caused by TNF. An alternative hypothesis is that increased IL-6 production represents a compensatory mechanism, whereby insulin-resistant individuals or individuals at risk of developing insulin resistance stimulate an alternative mechanism with regard to maintaining glucose homeostasis. Finally, chronically elevated IL-6 levels may simply reflect a feedback mechanism due to impaired IL-6 signaling. It is, however, not known if "IL-6 resistance" exists as a phenomenon in line with the fact that a chroni- cally elevated level of insulin or leptin most often reflects insulin resistance or leptin resistance, respectively.

\section{C-Reactive Protein (CRP)}

CRP is an acute phase protein, synthesized by heapatocytes, first described in 1930 by Tillet and Frances who identified a substance in the sera of patients acutely infected with pneumococcal pneumonia that formed a precipitate when combined with polysaccharide C of Streptococcus pneumonia [81]. Liver secretion of $\mathrm{CRP}$, follows the acute-phase protein's response, being secreted in response to stimulation by several cytokines, particularly IL-6, Il-1, TNF- $\alpha$. Like many acute phase protein, CRP is normally present in trace levels in serum but increases rapidly and dramatically in response to a variety of infectious or inflammatory conditions. However, recent data show that arterial tissue can produce CRP as well as complement proteins [82].

The exact function of CRP is largely unknown. But two functional properties of CRP including the ability to activate complement through the classic complement pathway, and the ability to modulate the function of phagocytic cells have been demonstrated.

Levels of CRP have been found to predict future risk among patients with stable and unstable angina, in the chronic phase of myocardial infarction, and among patients undergoing revascularization procedures $[82,83]$, prompting some to suggest it should be measured as a routine clinical risk assessment test, having relevant prognostic value in subjects with chronic heart disease (CHD) and with acute coronary syndromes (ACS) [35]. Furthermore, risk stratification of acute cardiac patients using CRP in addition to cardiac troponins showed how high CRP levels at hospital admission were associated with an increased incidence of recurrent angina, coronary revascularization, myocardial infarction, and cardiovascular death, indicating a bad outcome [84], a bad response to conventional therapy [85], and activation of pro-inflammatory and pro-atherosclerotic nuclear factor NF- $\kappa \mathrm{B}$ [86]. An important contribution to understanding the meaning of CRP high levels in ACS has been provided also from Liuzzo et al., showing that patients with coronary vasospasm have persistently normal CRP levels, despite frequent episodes of ST-segment elevation [87], suggesting that the rise in CRP may be secondary to an underlying proinflammatory state, rather than due to myocardial necrosis.

Furthermore, baseline levels of CRP are a strong independent predictor of risk of future myocardial infarction, stroke, peripheral vascular disease, and vascular death among healthy individuals including man and women without known vascular disease by several investigators $[88,89]$.

Monitoring of CRP levels has also increasing importance in appearing healthy subjects. Data in support of a role for CRP for cardiovascular risk prediction among apparently healthy individuals are robust and remarkably consistent across several European and US cohort. Several prospective studies, in the last years, have consistently shown that CRP is a powerful predictor of future first coronary event in apparently healthy men and women. Findings from Multiple Risk Factors Interventional Trail (MRFIT) demonstrated a direct positive association between CRP and coronary heart disease mortality in apparently healthy men followed over a 17-year period (RR: 2.8; 95\% CI, 1.4-5.4) [90,91]. In the analysis provided by Blake and Ridker, CRP was the single most powerful predicator of cardiovascular risk in all of the inflammatory and lipid markers. In this multivariate analysis, matched for age and smoking and adjusted for other cardiovascular risk factors, the authors found that only CRP and total cholesterol/high-density cholesterol (TC/HDL-C) ratio were independent predictors of future cardiovascular risk [82].

Real meaning of CRP increase in atherosclerotic patients is still hard to elucidate; CRP has been considerate a spillover of the inflammation related to the extent and severity of atherosclerosis or 
may reflects the amount and activity of circulating proinflammatory cytokines, such as TNF- $\alpha$, IL-1, and IL- 6 . But, in addition to being a marker of inflammation associated with atherosclerosis, some evidence suggests that CRP may also be a causal risk factor. Over the last several years, increasing evidence suggests CRP may contribute directly to the proinflammatory state, indicating that CRP may play a direct role in vascular injury process. Several reports demonstrated that CRP has been localized directly within atheromatous plaque where it precedes and mediates monocyte recruitment. So, CRP could be implicated in all phases of atherosclerosis, from the initial recruitment of inflammatory cells into the arterial wall to plaque rupture [14].

Direct atherosclerotic effects of CRP are related to a local effect into the arterial wall, colocalizing with the terminal complement complex and foam cells. CRP upregulates the expression of adhesion molecules, and mediate proinflammatory factor induction in several kinds of cells in artery wall as well as circulating monocytes [92]. It increases opsonization of LDL and mediates the uptake of LDL into the macrophages, which then become foam cells. It exerts particularly important effects on endothelial function by inducing endothelial cell expression of adhesion molecules, such as ICAM-1, VCAM-1 (vascular cell adhesion molecule-1) and P-selectin [93] inhibiting the expression and activity of eNOS (endothelial nitric oxide synthase) [34] and reducing prostacyclin release [94]. CRP also induces monocyte recruitment by up-regulating endothelial cell expression of MCP-1 (monocyte chemoattractant protein-1) [95] and induces monocyte chemotaxis by upregulating monocyte expression of the MCP-1 receptor CCR-2 (CC chemokine receptor-2) [96]. Together, these factors promote the recruitment, binding and uptake of inflammatory cells, such as macrophages and T-cells, into the artery wall. It has been shown to bind and opsonize LDLs in the artery wall, enhancing their uptake by macrophages [97], and activates the complement pathway [98], leading to the production of proinflammatory cytokines by vascular cells. CRP also promotes plaque instability by inducing endothelial expression of MMP (matrix metalloproteinase)-1 and MMP-10 [99], and promotes thrombosis by inducing the expression of PAI-1 (plasminogen activator inhibitor-1) [100].

Once considered just a marker of inflammation, this evidence indicates that CRP may be directly involved in the development and progression of atherosclerosis. However, some recent reports suggest that many of the inflammatory in vitro effects attributed to CRP may have been artifacts caused by the presence of contaminants in the CRP preparation used in the experiments [42]. Furthermore, the overexpression of CRP in ApoE-/- mice had either no effect [101] or produced only a modest increase [102] in atherosclerosis, and one report even indicates some protective effects of CRP on atherogenesis in mice [103]. As a result, there is considerable controversy in the literature as to whether CRP is directly involved in the development of atherosclerosis and its complications. More research will be needed clarify these issues.

\section{Interleukin-10 (IL-10)}

IL-10 is one of the main cytokines having a biological antiinflammatory effect. Circulating levels of Il-10 increases in the circulation after exercise, contributing to mediate the antiinflammatory effects of exercise. The concept that IL-10 acts as an anti-inflammatory molecule was suggested primarily by studies showing inhibition of the synthesis of a large spectrum of proinflammatory cytokines by different cells, particularly of the monocytic lineage. Thus IL-10 inhibits the production of IL-1 $\alpha$, IL-1 $\beta$, and TNF- $\alpha$ as well as the production of chemokines, including IL-8 and macrophage inflammatory protein- $\alpha$ from LPS-activated human monocytes $[104,105]$. These cytokines and chemokines play a critical role in the activation of granulocytes, monocytes/macrophages, natural killer cells, and $\mathrm{T}$ and $\mathrm{B}$ cells and in their recruitment to the sites of inflammation. Taken together, these observa- tions suggested that IL-10 plays an important role in orchestrating the inflammatory reaction involving macrophage/monocyte activation in particular.

IL-10 also prevents cytokine synthesis by posttranscriptional mechanisms, as shown in human macrophages where the inhibition of IL- 6 , IL- $1 \beta$, and TNF- $\alpha$ release induced by LPS is a direct consequence of mRNA degradation of their corresponding genes [106].

\section{Interleukin-1 receptor antagonist (IL-1 ra)}

Main biological role provided by IL-1ra is to inhibit signaling transduction through the IL-1 receptor complex [107]. The IL-1ra is a member of the IL-1 family that binds to IL-1 receptors but does not induce any intracellular response. Studies have demonstrated that IL-1ra is also an acute phase protein [108] because both cultured human hepatocytes and the human hepatoma cell line HepG2 produce IL-1 ra in response to stimulation with IL-6, confirming the biologic relation between the two molecules as seen during acute physical exercise.

\section{Fibrinogen}

Several large-scale epidemiologic studies demonstrate that baseline fibrinogen concentrations predict future risk of myocardial infarction and stroke $[109,111]$.

When compared head-to-head with CRP, fibrinogen seems a less potent predictor of cardiovascular events [112]. Illustrating the importance of detection methodology, when fibrinogen is measured with a reliable and high-quality immunoassay, there is a significant association between higher concentrations of fibrinogen and CRP, alone and in combination, and incident cardiovascular disease in apparently healthy women over a 10-year follow-up period [113].

\section{PART II - EFFECT OF A SINGLE BOUT OF EXERCISE ON INFLAMMATORY MARKERS OF ATHEROSCLEROSIS}

As underlined in the introduction, regular physical activity offers protection not only against several chronic cardiovascular metabolic and degenerative disease such as coronary heart disease [22], chronic heart failure [23], type 2 diabetes, [24], colorectal cancer and breast cancer [21], COPD [25], age-related cognitive decline [114,115], and dramatically reduces all-cause mortality [116], but it is also effective against different mechanisms involved in the low-grade inflammation that may be found both in several of the pathologic conditions cited before, but also in the appearing healthy individual. In a great part of this chronic diseases regular physical exercise provide effective protection in primary prevention and could be used as a therapeutic option to modify natural history in secondary prevention.

Several of these benefits seen after regular physical exercise are mediated by the metabolic changes induced by training. Infact, exercise training involves multiple metabolic adaptations including increased preexercise skeletal muscle glycogen content, enhanced activity of key enzymes involved in the $\beta$-oxidation [117], increased sensitivity of adipose tissue to epinephrine-stimulated lipolysis [118], and increased oxidation of intramuscular triglycerides [119], whereby the capacity to oxidize fat is increased [120]. As a consequence, the trained skeletal muscle is less dependent on plasma glucose and muscle glycogen as substrate during exercise [121].

An increasing number of papers in the last decade have documented that self-reported physical activity or physical performance is correlated inversely with systemic low-grade inflammation [122132] clearly demonstrated by the analysis of circulating inflammatory parameters, although the lack of an association has also been reported [133], especially when adjusting for other factors in multivariate analyses [134,135].

In the InCHIANTI study [122], a prospective population-based study of older people, aimed at identifying risk factors for late-life 
disability, that consisted of 1020 participants aged 65 years and older living in the Chianti area of Italy, inflammation, measured as high levels of IL-6, CRP, and IL-1RA, was significantly associated with poor physical performance and muscle strength in older persons. In the ATTICA Study [123], a high self-reported degree of physical activity is associated with attenuated circulating levels of TNF- $\alpha$, IL-6, CRP, and SAA compared with those devoted to a sedentary lifestyle, independently of gender, age, smoking habits, BMI, total cholesterol, blood glucose, and blood pressure. Additionally, a similar association is observed in the same population when taken in account a subgroup with the metabolic syndrome and within a subgroup without [124]. Thus, a high level of physical activity is apparently associated with reduced levels of peripheral inflammatory mediators in the range of $20-60 \%$ compared with a sedentary lifestyle, although different degrees of reduction of inflammatory markers may be found in relation to exercise type, duration and intensity [127].

These correlation data do, however, not necessarily provide any information with regard to a possible causal relationship. However, several studies performed both in healthy and in unhealthy people, thus in presence of pathologic condition affecting the physiologic inflammatory asset, have reported that controlled exercise intervention programs reduce systemic low-grade inflammation in patients with coronary heart disease [136], peripheral artery disease [137], chronic heart failure [138] and in healthy, young adults [139]. A failure of a positive effect has been reported in old nursing home patients [140] and in obese elderly [141].

Nevertheless the great part of available data confirm how physical fitness is linked to low systemic low-grade inflammation, possible explanation of the discrepancies observed between selfreported physical activity and systemic inflammatory markers in the various trial that tried to address this issue might be due to different experimental conditions: a large interpersonal variability in peripheral inflammatory markers together with a considerable coefficient of variability in high sensitivity cytokine essays make difficult to standardize cut off of the variables analyzed (healthy adult male vs healthy adult female vs older, etc etc). Finally, the effect of physical activity is likely differentiated in disorders associated with systemic low-level inflammation. It is probably easier to revert endothelial dysfunction, insulin resistance, and dyslipidaemia in CVD than cachexia in a terminal state. In this regard, it is possible that there is a threshold beyond which systemic low-level inflammation represents an irreversible state; e.g., among patients with chronic heart failure, exercise training reduces plasma levels of TNF- $\alpha$ significantly among survivors but not among nonsurvivors [142].

Nevertheless the discrepancies observed in the available data, that will be deeper analyzed in the latter part of this review and the lack of appropriated studies in a so relevant matter like the relationship between physical exercise and inflammation, certainly, the demonstration that skeletal muscle during contraction prodeces and then releases in the circulation several myokines, open a new frontier in research the relationship between myokines and metabolism both in physiologic and in pathologic conditions. Because systemic markers of inflammation are elevated in CVD and other chronic diseases, modifying their levels through exercise may have therapeutic potential; in this point of view it is essential to assess how the systemic low-grade inflammation balance associated to CVD conditions is modified by muscular-related cytokines released after chronic training.

\section{Acute Changes of Systemic Inflammatory Markers During and After Exercise}

For most of the last century, researchers sought a link between muscle contraction and humoral changes in the form of an "exercise factor," which could be released from skeletal muscle during contraction and mediate some of the exercise-induced metabolic changes in other organs such as the liver and the adipose tissue. In the latest years, with the discovery that cytokines or other peptides (classified as "myokines") produced, expressed, and released by muscle fibers could exert either paracrine or endocrine effects a possible link between skeletal muscle contractile activity and immune changes was established (see Fig. (1)).

So, muscle contraction during exercise results in a systemic cytokine cascade, considerable changing the immune system activity.

In the year 2000, it became clear that contracting human skeletal muscle releases significant amounts of IL-6 into the circulation during prolonged single-limb exercise [143]. An accompanying editorial to this publication pointed to the possibility that musclederived IL- 6 could have metabolic roles: "It is an intriguing possibility that the IL- 6 response may be a signal indicating that muscle glycogen stores are reaching critically low levels and that the active muscles' reliance on blood glucose as a source of energy is on the increase" [144]. The latter statement was soon supported by experimental studies $[145,146]$, and a number of studies highlighted the fact that muscle-derived IL-6 is an important player in metabolism [51, 147-149].

The identification of skeletal muscle as a cytokine-producing organ soon led to the discovery that muscle-derived cytokines could account not only for exercise- associated immune changes, but that these muscle-derived cytokines played a role in mediating the exercise associated metabolic changes, as well as the metabolic changes following training adaptation. It appears that skeletal muscle has the capacity to express several myokines. To date the list includes IL-6, IL-8, and IL-15 [148]. Contractile activity plays a role in regulating the expression of many of these cytokines in skeletal muscle [148].

IL-6 is the first cytokine present in the circulation during exercise; the appearance of IL- 6 in the circulation is by far the most marked and its appearance precedes that of the other cytokines [149]. The level of circulating IL-6 increases rapidly in an exponential fashion (up to 100-fold) in response to acute exercise and declines in the postexercise period [12,150]. IL-6 levels elevation is followed by an increase of circulating levels of other well-known anti-inflammatory cytokines, cytokine inhibitors and inflammatory markers downstream in the acute-phase response, such as IL-1ra, IL-10 and sTNF-R [97,99]. Taken together, exercise provokes an increase primarily in IL-6, followed by an increase in IL-1ra and IL-10 (see Fig. (2)). Concentrations of the chemokines, IL-8, macrophage inflammatory protein $\alpha$ (MIP-1 $\alpha)$, and MIP- $1 \beta$ are elevated after strenuous exercise [149]. In most exercise studies, tumor necrosis factor (TNF- $\alpha$ ) does not change. When young, healthy men perform $180 \mathrm{~min}$ of a knee extensor exercise, TNF- $\alpha$ mRNA increases only slightly (approximately fourfold, $\mathrm{P}=0.08$ ) during the first $30 \mathrm{~min}$ of exercise, and after this time, it does not increase any further, whereas IL-6 increases 100-fold in the same model $[151,152]$. Consistent with this, there is no measurable increase in systemic levels, and there is not detectable TNF- $\alpha$ net release from the working legs; only highly strenuous, prolonged exercise such as marathon running results in a small increase in the plasma concentration of TNF- $\alpha[151,152]$.

So, usually, the cytokine response to exercise and sepsis differs with regard to TNF- $\alpha$. Thus, physical exercise is associated with a systemic cytokine response comparable with the levels observed during severe infections or sepsis, except the important difference that increases in TNF- $\alpha$ and IL- $1 \beta$ are really minute if present at all when concentric exercise without muscle damage is performed.

Following exercise, not necessarily the basal plasma IL-6 concentration might rapidly increase to the maximum levels reported (up to 100-fold respect to basal levels), infact less dramatic increases are more frequent $[12,153]$, instead major increase (up to 8.000 -fold) are exceptional and subsequent to extreme physical exercises [154]. The peak IL-6 level is reached at the end of the exercise or shortly thereafter [155], followed by a rapid decrease 


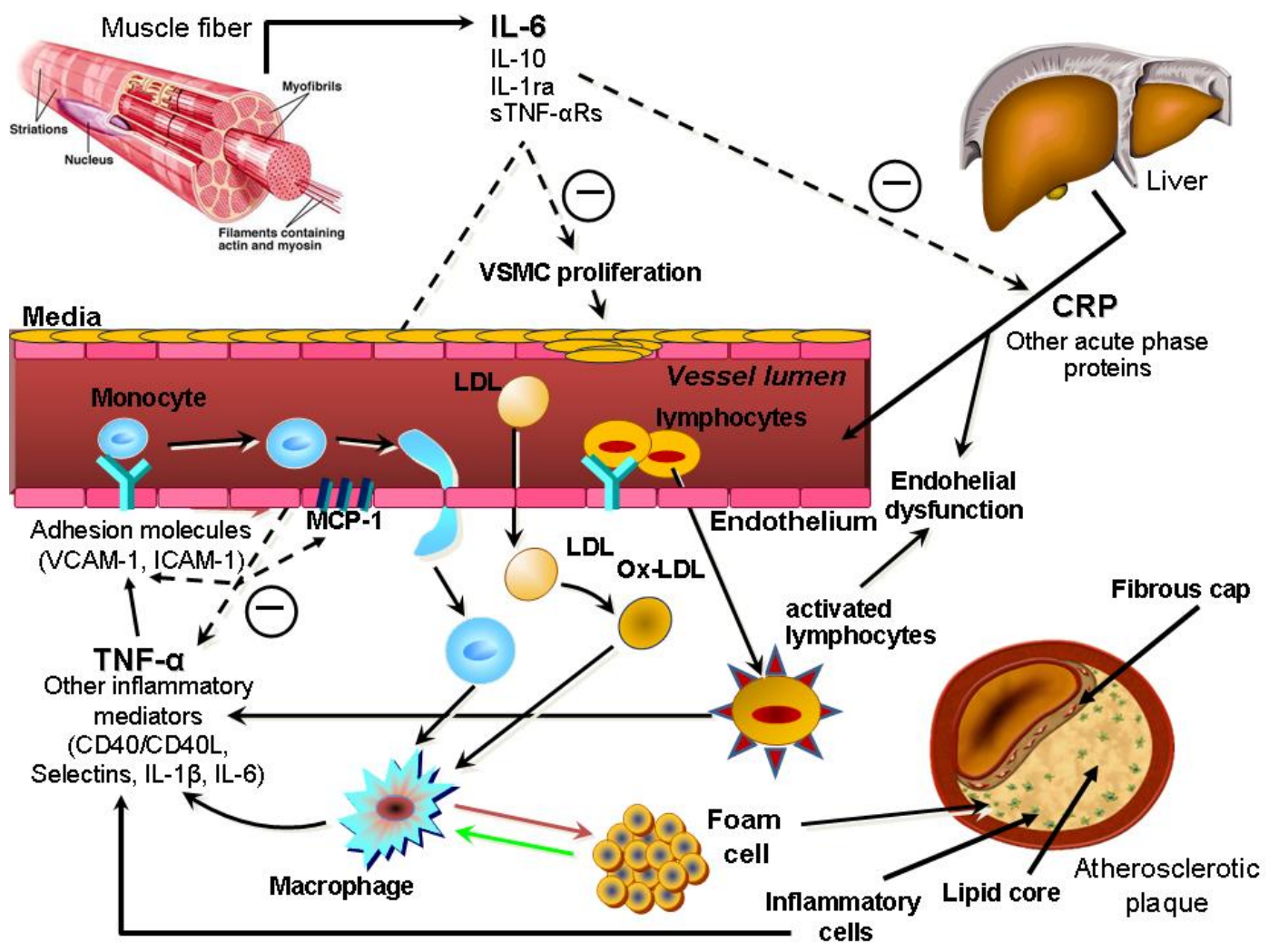

Fig. (1). Overview of main known mechanisms through regular physical activity influences chronic systemic inflammation of atherosclerotic patient : Schematic representation of the main events of inflammation process in atherosclerosis and of the influence of myokines produced during muscle contraction. Broken arrows indicates inhibitory or regulatory effect of physical activity-induced anti-inflammatory mediators. See text for more details about the different mechanisms.

ICAM-1, intercellular cell adhesion molecule-1; VCAM-1, vascular cell adhesion molecule-1; MCP-1, monocyte chemoattractant protein-1; IL, interleukin; IL-1ra: Interleukin-1 receptor antagonist; TNF- $\alpha$ : tumor necrosis factor-alpha; VSMC: Vascular Smooth Muscular Cell; CRP: C-Reactive Protein; sTNF- $\alpha$ Rs: soluble TNFa; receptors; CD40L: CD40 ligand; LDL: Low Density Lipoprotein; ox- LDL: oxidized LDL

towards pre-exercise levels. Young healthy individuals performed 3 $\mathrm{h}$ of dynamic two-legged knee-extensor exercise at $50 \%$ of their individual maximal power output. This exercise induced an only moderate increase in heart rate (113 to 122 beats/min) but induced a 16-fold increase in IL-6 mRNA, a 20-fold increase in plasma-IL-6, and a marked IL-6 release from working muscle [155]. When the same model was applied in elderly healthy untrained subjects, even higher amounts of IL-6 were released from working muscle during exercise at the same relative intensity [12]. Overall, the combination of mode, intensity, and duration of the exercise determines the magnitude of the exercise-induced increase of plasma IL-6 [12].

The discovery that IL-6 is released from contracting skeletal muscle has generated much interest among the scientific community because this finding is somewhat paradoxical. On one hand, IL-6 is markedly produced and released in the postexercise period when insulin action is enhanced, but on the other hand, IL-6 has been associated with obesity and reduced insulin action.

An initial study suggested that increased systemic levels of inflammatory parameters were related to muscle damage, as increased IL-6 levels were first detected in eccentric exercise models in which a positive correlation was also demonstrated to considerable creatine kinase (CK) increases [156]. However, later studies have not confirmed an association between peak IL-6 and peak CK levels. Moreover, it has become evident that eccentric exercise is not associated with a larger increase in plasma IL-6 than exercise involving concentric "nondamaging" muscle contractions, clearly demonstrating that muscle damage is not required to increase plasma IL-6 during exercise. Rather, eccentric exercise may result in a delayed peak and a slower decrease of plasma IL-6 during recovery [157-159].

The IL-6 response is sensitive to the exercise intensity [160], which again indirectly represents the muscle mass involved in the contractile activity. Since contracting skeletal muscle per se is an important source of IL- 6 found in the plasma [143,155], it is not surprising that exercise involving a limited muscle mass, e.g., the muscles of the upper extremities, may be insufficient to increase plasma IL-6 above pre-exercise level [161-163]. In contrast, running, which involves several large muscle groups, is the mode of exercise where the most dramatic plasma IL-6 increases have been observed. Fischer [153] has shown that exercise duration is the single most important factor determining the post-exercise plasma IL-6 amplitude. In fact, more than $50 \%$ of the variation in plasma IL-6 following exercise can be explained by exercise duration [153].

Since exercise at high intensity is often associated with shorter duration of the exercise, and vice versa, the relationship between the plasma IL-6 increase and the duration may be even more pronounced if adjusted for the exercise intensity. Accordingly, 6 min of maximal rowing ergometer exercise may increase plasma IL-6 2fold [164], but more than 10-fold increases of plasma IL-6 have not been observed in response to exercise lasting less than $1 \mathrm{~h}$.

The fact that IL-6 is synthesized and released from contracting muscles alone and not from resting muscles exposed to the same hormonal changes $[143,165]$. In young men who perform a one-leg knee extensor exercise, IL-6 production in working muscles can account for the increase in plasma IL-6 during exercise when arte- 


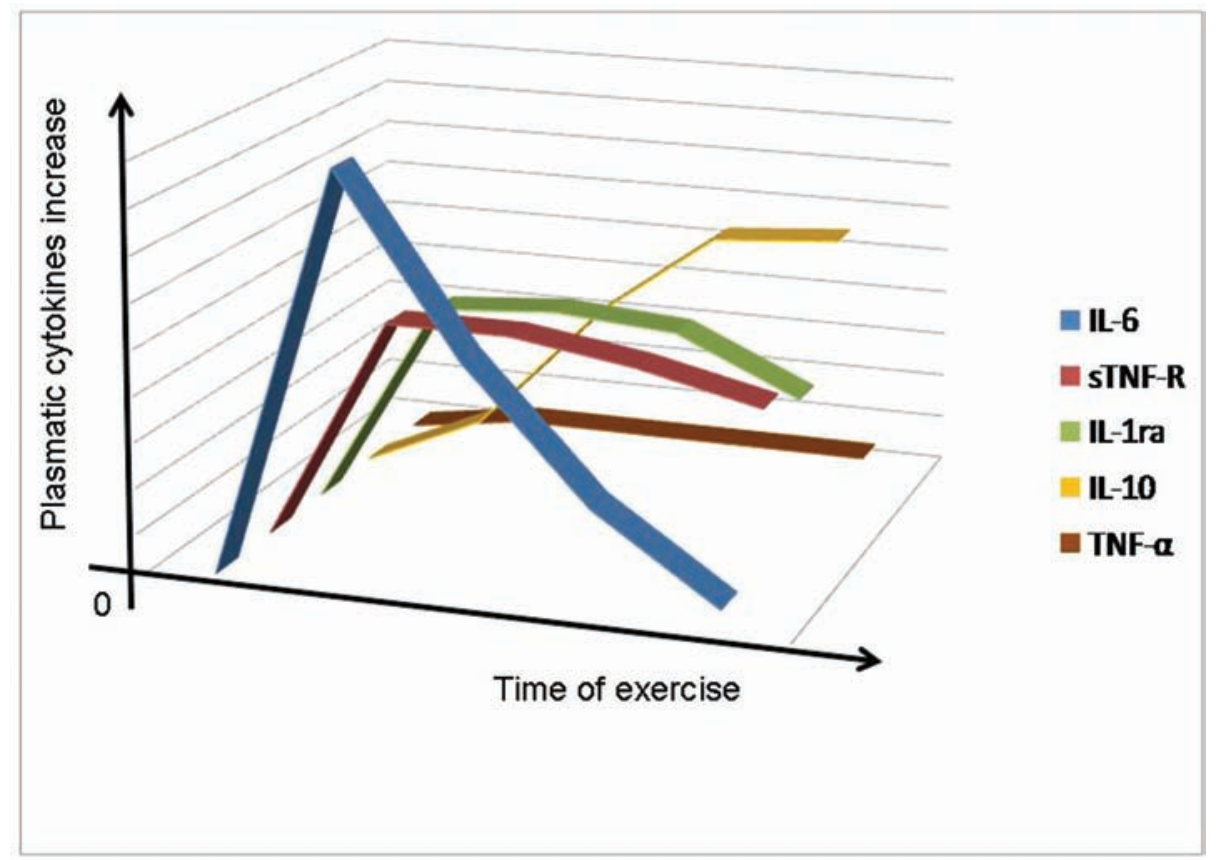

Fig. (2). Schematic view of exercise-induced increases in circulating cytokines. ( [12], modified).

The level of circulating IL-6 increases rapidly in an exponential fashion (up to 100-fold) in response to acute exercise and declines in the postexercise period. IL-6 levels elevation is followed by an increase of other anti-inflammatory cytokines, cytokine inhibitors and inflammatory markers downstream in the acutephase response, such as IL-1ra, sTNF-R, IL-10, IL-8 and IL-15 (the last two not showed in the graphic). Usually, TNF- $\alpha$ levels do not increase in response to exercise.

IL: Interleukin; sTNF-R: soluble Tumor Necrosis Factor - Receptor; TNF- $\alpha$ : Tumor Necrosis Factor- $\alpha$.

rial-femoral venous differences are measured over the exercising and the resting leg and adjusted for the blood flow [143]. This demonstrates that circulating systemic factors cannot explain why contracting muscles synthesize and release IL-6. It is more likely that local factors are involved, although systemic factors may modulate the IL-6 release from contracting muscle. Immunohistochemical studies of skeletal muscle have demonstrated that type 1 and type 2 muscle fibers show marked and homogenous staining of IL-6 protein following exercise with a different, predominant accumulation, depending on the mode, intensity, and duration of the performance [165].

After there was ascertained that contracting muscle is able to produce cytokines, a great part of the efforts of the studies in this matter were concentrated in the attempt to determine what was the source of the IL- 6 production into the muscle. Being certain that monocytes are the main source of Il-6 during common immune response during sepsis or local infections, the first hypothesis tested was that immune cells were responsible of IL-6 increase during exercise [166], but early different groups demonstrated that IL-6 mRNA in monocytes did not increase as a result of exercise $[167,168]$. These and other subsequent works clearly demonstrated that monocytes are not the source of the exercise-induced increase in plasma IL-6. Starkie et al. [169] demonstrated that the number, percentage, and mean fluorescence intensity of monocytes staining positive for IL-6 either do not change during cycling exercise [169] or do in fact decrease during prolonged running [170]. Excluded monocytes, seems today to be very clear that the contracting skeletal muscle per se is the main source of the IL- 6 in the circulation in response to exercise. In resting human skeletal muscle, the IL-6 mRNA content is very low, while small amounts of IL-6 protein predominantly in type I fibers may be detected using sensitive immunohistochemical methods [171]. In response to exercise, an increase of the IL-6 mRNA content in the contracting skeletal muscle is detectable after $30 \mathrm{~min}$ of exercise, and up to 100 -fold increases of the IL- 6 mRNA content may be present at the end of the exercise bout $[172,173]$. Nevertheless this, although the earlier studies demonstrated that IL-6 mRNA is increased in skeletal muscle biopsy samples, they did not prove that skeletal muscle is the source of the increase in the contraction-induced increase in IL-6. Today, it is not yet fully clear which cell type within the muscle is responsible for the production.

Whereas myoblasts had been shown to be capable of producing IL-6 [174,175], endothelial cells [176], fibroblasts [175], and smooth muscle cells [177] had been shown to produce IL-6 under certain circumstances. Langberg et al. [178] demonstrated that IL-6 is produced by the peritendinous tissue of active muscle during exercise. In an attempt to determine which cells produce the IL-6, Keller et al. [179] isolated nuclei from muscle biopsies obtained before, during, and after exercise. In this work the authors demonstrated that the nuclear transcription rate for IL-6 increases rapidly and markedly after the onset of exercise [179]. This suggested that a factor associated with contraction increases IL-6 transcriptional rate, probably in the nuclei from myocytes, given the observation that IL-6 protein is expressed within muscle fibers [180]. Further evidence that contracting muscle fibers themselves are a source of IL-6 mRNA and protein has been achieved by analysis of biopsies from the human vastus lateralis using in situ hybridization and immunohistochemistry [181,182]. In addition, assessment of the interstitial IL-6 concentration using microdialysis indicates that the concentration of IL- 6 within the contracting skeletal muscle may be 5to 100 -fold higher than the levels found in the circulation [183, 184]. Accordingly, IL-6 appears to accumulate within the contracting muscle fibers as well as in the interstitium during exercise. However, it has been the simultaneous measurement of arteriovenous IL-6 concentrations and blood flow across the leg that has demonstrated that large amounts of IL-6 are released from the exercising leg [143].

As mentioned above, very high concentrations of IL-6 have been detected along the Achilles' tendon using microdialysis in 
response to prolonged running [183], but since the muscle mass involved in exercise is much higher than the mass comprised by tendons, the mutual contribution of peritendinous versus musclederived IL-6 to the systemic IL-6 is unclear. In addition, a small net release of IL-6 from the internal jugular vein has been reported, suggesting that the central nervous system may contribute to the IL6 found in the circulation [185]. The findings are contrasted by the consistent findings that peripheral blood mononuclear cells do not contribute to the IL-6 found in the circulation of healthy subjects, neither at rest nor in response to exercise [169,187-188]. The adipose tissue may contribute markedly to IL-6 in the circulation at rest $[10,189]$. However, although IL-6 mRNA levels increase in adipose tissue during exercise [190], measurement of arteriovenous plasma IL-6 differences across the abdominal subcutaneous adipose tissue bed shows that this compartment does not contribute to the exercise-induced IL- 6 in the circulation until the recovery phase [191]. Since almost any cell type may synthesize IL-6 upon adequate stimulation [192], further studies may discover other sites contributing to the IL-6 in the circulation in response to exercise.

\section{Is the Muscle IL-6 Release a Metabolic-related Event?}

A very interesting aspect of the relationship between human skeletal muscle contraction and Il-6 release concerns the repeatedly confirmed data that about the observed autonomy of IL-6 production from TNF- $\alpha$. It seems that this phenomenon rather than an inflammation-related event could be metabolic-related [193,194].

During exercise, skeletal muscles need to increase the uptake of glucose and FFA to generate adenosine 5-triphosphate (ATP) and to quickly refill glycogen pools. Several metabolic genes are transcriptionally activated in the recovery phase from exercise, presumably with the purpose to rebuild energy stores [194]. If IL-6 is an energy sensor in the muscle, and IL-6 is released when the local glycogen content is low, it is possible that the large amounts of musclederived IL-6 in the circulation act as a hormone with the purpose to mobilize extracellular substrates and/or to augment substrate delivery during exercise [145]. So, this interesting link between IL-6 production and muscle metabolism seems to have a strong relation to glycogen muscular content. both intramuscular IL-6 mRNA expression [145] and protein release [146] are exacerbated when intramuscular glycogen is compromised, suggesting that IL-6 is somehow related to glycogen content.

IL-6 induces lipolysis and increased fat oxidation without causing triacylglycerolemia when it is administrated in doses mimicking systemic levels during exercise [195] as well as higher doses [196]. Consistent with this, IL-6 induces lipolysis in 3T3-LI adipocytes and increases fat oxidation in myotubes and in isolated rat soleus muscle [197]. In addition, it has been suggested that IL-6 influences glucose homeostasis during exercise [198-200]. In the latter study, young men performed a bicycle exercise at three separate occasions, at a relative high intensity or at a low intensity, with or without an infusion of recombinant (r)IL-6, which matched the circulating concentration of IL-6 in the high-intensity trial. It was demonstrated by the use of stable isotopes that the endogenous glucose production, whole-body glucose disposal, and the metabolic clearance rate of glucose were higher during the rIL-6 infusion + low intensity exercise than low-intensity exercise alone, despite identical exercise intensities and the same levels of insulin, glucagon, epinephrine, norepinephrine, cortisol, and growth hormone [165]. This finding implicates an entirely novel understanding of the role for IL-6 in glucose production and clearance.

Adding to what we knew about this topic, recently a number of studies have clearly demonstrated that glucose ingestion during exercise attenuates the exercise-induced increase in plasma-IL-6 [195,197-200]. This effect has been demonstrated for different types of training, for example running or cycling $[199,200]$. However, whereas supplementation with carbohydrates during exercise inhibits the exercise-induced increase of IL-6 in plasma, IL-6
mRNA expression within the contracting muscle is unaffected $[201,202]$. As carbohydrate availability is reduced, the sympathoadrenal response to exercise is exacerbated, and it has been suggested that epinephrine may stimulate IL-6 gene transcription via $\beta$ adrenergic stimulation of protein kinase A.

Accordingly to this experimental observations, there is evidence in support of the hypothesis that during physical exercise, IL-6 has the capacity to act in a "hormone-like" manner to direct the metabolism toward enhanced energy supply to working skeletal muscles, exerting especially strong effects on adipose tissue.

During acute exercise, in addiction to high circulating levels of IL-6 and subsequently IL-1ra, IL-10 and sTNF-R, also other myokines are secreted: IL- 8 and IL- 15 .

$\boldsymbol{I L} \mathbf{- 8}$ belongs to the CXC family of chemokines. The CXC nomenclature relates to the presence of two conserved cysteine residues at the $\mathrm{NH} 2$ terminus separated by one amino acid. IL- 8 is a known chemokine that attracts primarily neutrophils. In addition to its chemokine properties, IL-8 acts as an angiogenic factor.

IL-8, like IL-6, is influenced by physical activity. The systemic plasma concentration of IL- 8 increases in response to exhaustive exercise such as running, which involves eccentric muscle contractions [203-205]. In contrast, concentric exercise such as bicycle ergometry [206] or rowing [207] of moderate intensity does not increase plasma IL-8 concentration. However, intense cycle ergometry has been reported to increase IL-8 plasma concentration to a small degree [208]. The possibility of contracting skeletal muscle expressing IL-8 has been evaluated by Nieman et al. [203]. These authors showed that a severalfold increase in IL- 8 mRNA could be found in skeletal muscle biopsies from subjects having completed a 3-h treadmill run concomitantly with increased plasma levels of IL8 [203]. Similarly, IL-8 mRNA increased in response to $1 \mathrm{~h}$ of cycle ergometry exercise, but with no change in the plasma concentration of IL-8 [206]. IL-8 protein was recently demonstrated to be clearly expressed in human skeletal muscle as a response to concentric exercise [209]. The finding of a marked increase of IL- 8 mRNA in muscle biopsies during and following exercise, and IL-8 protein expression within skeletal muscle fibers in the recovery from exercise, strongly indicates that exercise per se stimulates muscle cells to produce IL-8. This is in accordance with the finding that muscle cells in vitro have the capacity to express IL-8 both at the mRNA and protein levels [210].

The physiological function of IL-8 within the muscle is still unknown. The main part of the systemic increase in IL-8 as seen during exercise with an eccentric component is most likely due to an inflammatory response. In accordance with this, several groups observed that there is not increase in the systemic IL-8 plasma concentration during or after concentric exercise [203,206,209]. However, when measuring the arteriovenous concentration difference across a concentrically exercising limb, we detected a small and transient net release of IL-8, which did not result in an increase in the systemic IL-8 plasma concentration [209]. The fact that a high local IL-8 expression takes place in contracting muscle with only a small and transient net release may indicate that muscle-derived IL8 acts locally and exerts its effect in an autocrine or paracrine fashion. A plausible function of the muscle-derived IL-8 would be chemo-attraction of neutrophils and macrophages when, in fact, in concentric exercise there is little or no accumulation of neutrophils or macrophages in skeletal muscle.

A more likely function of muscle-derived IL-8 is to stimulate angiogenesis. IL-8 associates with the CXC receptor 1 and 2 (CXCR1 and CXCR2). It induces its chemotactic effects via CXCR1, whereas CXCR2, which is expressed by human microvascular endothelial cells, is the receptor responsible for IL-8-induced angiogenesis [211-213].

IL-15 (14-15 kDa) is a four- $\alpha$-helix cytokine with structural similarities to IL-2 [214,215]. Two isoforms of IL-15 with altered 
glycosylation have been shown to exist: a long signaling peptide form (48 amino acids) that is secreted from the cell, and a short signaling peptide (21 amino acids) form that remains intracellular, localized to nonendoplasmic regions in both cytoplasmic and nuclear compartments. Cell membrane expression might be crucial in mediating an extracellular function rather than secretion and, in part, explains the difficulty in detecting soluble IL-15 in biological systems. IL-15 functions via a widely distributed heterotrimeric receptor (IL-15R), which consists of a $\beta$-chain (shared with IL-2).

The regulatory role of muscle contraction with regard to IL-15 is unclear. Nieman et al. (203) found that muscle IL-15 mRNA levels were unchanged immediately after a 3-h run, and Ostrowski et al. [216] found that plasma IL-15 (measured up to $6 \mathrm{~h}$ into recovery) did not change in response to $2.5 \mathrm{~h}$ of treadmill running. Skeletal muscle IL-15 mRNA levels, measured immediately after a 2-h weight training bout, did not differ from baseline [199], whereas plasma IL-15 protein was increased immediately after acute resistance exercise in one study [217].

IL-15 has been identified as an anabolic factor, which is highly expressed in skeletal muscle [218]. Furthermore, IL-15 has been suggested to play a role in muscle-adipose tissue interaction [219]. In human skeletal myogenic cultures, IL-15 induces an increase in accumulation of the protein myosin heavy chain (MHC) in differentiated muscle cells, suggesting IL-15 as an anabolic factor in muscle growth [220], and IL-15 stimulates myogenic differentiation independently of insulin-like growth factors (IGFs) [221]. Moreover, in opposition to the growth factor IGF-I, IL-15 has effects on fully differentiated myoblasts [222]. The potential therapeutic effect of IL-15 was demonstrated in an in vivo model, which demonstrated that IL-15 was able to antagonize the enhanced muscle protein breakdown in a cancer cachexia model. Interestingly, while IL-15 has been reliably demonstrated to have anabolic effects on skeletal muscle in vitro and in vivo, IL-15 seems to play a role in reducing adipose tissue mass. When IL-15 was administered to adult rats for 7 days, it resulted in a $33 \%$ decrease in white adipose tissue mass [223]. These findings provide support for the hypothesis that IL-15 functions in a muscle-to-fat endocrine axis that modulates fat: lean body composition and insulin sensitivity.

The list of the substances providing relevant metabolic effects produced by skeletal muscle fibres during contraction is rapidly increasing. It has recently been reported that adiponectin mRNA and protein are also expressed in skeletal muscle in response to in vivo lipopolysaccharide (LPS) administration in mice and following in vitro incubation with TNF- $\alpha$ and IFN- $\gamma$ in combination, but not IL-6 or IL-1 $\beta$ in human myotubes [224].

Adiponectin is an adipocytokine product of adipose tissue, which exerts insulin-sensitizing activity on the liver and skeletal muscle, antiatherogenic, and antiinflammatory effects, and inhibits TNF- $\alpha$ production and endothelial activation induced by TNF- $\alpha$ [224]. An important autocrine/paracrine factor in adipose tissue, it modulates the differentiation of preadipocytes and favors the formation of mature adipocytes.

It is well assumed that adiponectin concentrations are lower in obese than lean individuals. This is one of the main metabolic changes linking adipokines with the systemic pro-inflammatory asset observed in the patients affected by the metabolic syndrome, infact this adipokine functions as an endocrine factor, influencing whole-body metabolism via effects on target organs: adiponectin exerts multiple biologic effects pivotal to cardiovascular biology, including increasing insulin sensitivity, reducing visceral adipose mass, reducing plasma triglycerides, and increasing high-density lipoprotein (HDL) cholesterol [224]. Adiponectin, furthermore, alters the concentrations and activity of enzymes responsible for the catabolism of triglyceride-rich lipoproteins and HDL, such as lipoprotein lipase and hepatic lipase. All this alterations of the metabolic and lipid profile might affect atherosclerosis by modifying the balance of atherogenic and antiatherogenic lipoproteins in plasma. Adiponectin also directly affects the function of endothelial cells, reducing VCAM-1 expression, and macrophages, decreasing the expression of scavenger receptors through the modulation of the production of TNF- $\alpha$.

\section{Acute Exercise is a Pro-oxidant Stimulus}

Given that acute exercise is associated to a circulating release of myokines with a change in systemic immunologic state that is able to interfere with low-grade chronic inflammation of several pathologic conditions, it is also well demonstrated that acute exercise promotes oxidative stress. This finding, mediated by whole-body considerable increase of $\mathrm{VO}_{2}$ (oxygen consumption) during exercise could also seems paradoxical, such as the circulating release during exercise of pro-inflammatory cytokines such as IL-6.

The finding that exercise promotes oxidative stress in humans was first reported over 30 years ago, in 1978 [225]. This work revealed that $60 \mathrm{~min}$ of endurance exercise at $60 \%$ of VO2 max results in increased levels of expired pentane (biomarker of lipid peroxidation) and that supplementation with the antioxidant vitamin $\mathrm{E}$ reduced both resting and exercise-induced pentane production. The authors concluded that exercise promotes increased oxidant production but the source of this increased oxidant production was unidentified. Since this early observation, many studies using both animal and human subjects have demonstrated that a variety of exercise intensities and exercise modes (e.g., cycling, running, and resistance exercise) result in increased biomarkers of oxidative damage in both blood and skeletal muscle [226-230]. Only few studies have tried to find out the primary sources of reactive oxygen species (ROS) production during exercise, although we know that several tissue can produce ROS during exercise [231]. The lack of in vivo studies on this topic is due to the difficulty of investigating the multifaceted nature of exercise, which involves several organ systems that are connected through the increased energy requirement of contracting skeletal muscles [231]. Since the discovery that contracting skeletal muscles produce ROS [225], many investigators have assumed that skeletal muscle provides the major source of free radical and ROS generation during exercise [231]. Nonetheless, other tissues such as the heart, lungs, or blood may also contribute to the total body generation of ROS during exercise [231,232].

Studies about local consequences of ROS production in skeletal muscle showed how ROS influence the skeletal muscle force production in both unfatigued and fatigued muscle.

The low levels of ROS present in skeletal muscle during basal conditions are a requirement for normal force production [233,234]. Indeed, depletion of ROS from unfatigued skeletal muscle results in decreased muscle force production [235-237]. In contrast, a small increase in ROS production in skeletal muscle fibers promotes an increase in force production [235] (see Fig. (3)). The positive impact of ROS on muscle force production is reversed at high ROS concentrations as force production decreases in a dose-dependent manner [235]. So, local skeletal muscular cellular redox disturbances can significantly reduce skeletal muscle force production. This consistent observation suggests that contraction-induced ROS production can contribute to muscular fatigue during prolonged and intense exercise. Obviously, systemic spillover of redox muscular abnormalities cause a response due to anti-oxidant activity of specific enzymes, clearly seen during chronic adaptations to training.

Into the cell the increased oxygen flux through the mitochondrial electron transport chain is believed to be the main source of free radical generation during exercise, but many metabolic pathways differently in various tissues contribute to the generation of free radicals by reactions during exercise through the induction of enzymes such as xanthine oxidase, NADPH oxidase and myeloperoxidase [238]. The induction of these pro-oxidant enzymes by skeletal muscle and other tissues leads to an increase in plasma 


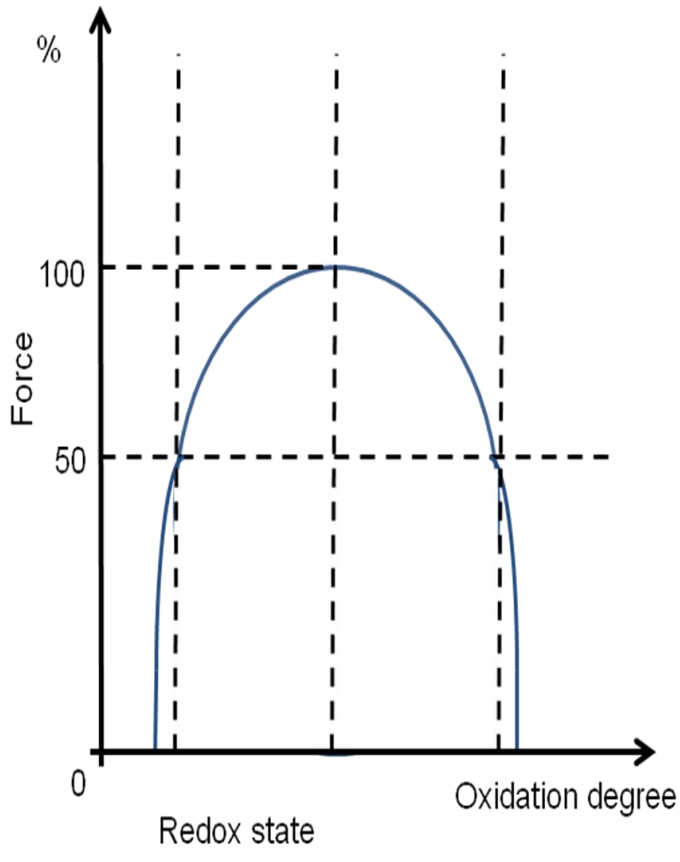

Fig. (3). Hypothetical model linking skeletal muscle redox state and force production proposed by Reid et al. in 1993 ([235], modified).

Low levels of reactive oxygen species (ROS) from unfatigued skeletal muscle results in decreased muscle force production. In contrast, a small increase in ROS production in skeletal muscle fibers promotes an increase in force production. The positive impact of ROS on muscle force production is reversed at high ROS concentrations as force production decreases in a dose-dependent manner. See text for more details.

markers of oxidative stress, such as F2-isoprostanes and myeloperoxidase. Circulating levels of these markers are independently associated with CVD risk [239,240], but it is unclear if oxidative stress in the circulation directly promotes the oxidation of LDL in the vascular wall and so could promote or exacerbate the atherosclerotic damage. Further elements about this concept are provided by Wetzstein et al. [241], who have shown that acute exercise increases the susceptibility of LDL to undergo in vitro oxidation, implying that this may also happen in the circulation. However, oxLDL in the plasma is cleared rapidly by the liver [242], so probably the circulating oxidation of LDL particles does not necessarily promote inflammation like LDL that is oxidized and retained in the artery wall. There is even evidence that plasma oxidative stress may be atheroprotective. Meilhac et al. [243] have shown that acute exercise in mice increases antibodies to oxidatively modified lipoproteins in the plasma, but this was associated with the induction of the antioxidant enzyme catalase in the vascular wall after just 1 week of exercise. This indicates that an exercise- induced plasma oxidative stress may stimulate an arterial antioxidant response, which should inhibit LDL oxidation, inflammation and ultimately atherosclerosis [243]. Additional studies are needed to confirm this hypothesis.

In contrast to acute exercise, chronic exercise appears clearly to enhance antioxidant defences in skeletal muscle, the circulation and the vasculature by a variety of mechanisms. In skeletal muscle, exercise training increases the activity of the antioxidant enzymes glutathione peroxidise and SOD (superoxide dismutase) [238]. These adaptations may dampen the metabolic perturbations in skeletal muscle induced by bouts of acute exercise. Chronic exercise also reduces markers of oxidative stress in the plasma, including F2-isoprostanes [244] and myeloperoxidase [245]. In the vasculature, exercise training induced increases in eNOS activity have many direct and indirect effects on oxidative stress and inflammation. Lastly, endothelium-derived NO may reduce inflammation in the artery wall by inhibiting activation of $\mathrm{NF}-\mathrm{\kappa B}$ (nuclear factor $\kappa \mathrm{B})$. NF- $\kappa \mathrm{B}$ is a transcription factor that is involved in the regulation of many of the pro-inflammatory genes linked to atherosclerosis, and probably mediates many of the anti-atherogenic effects ascribed to NO, including inhibiting leucocyte binding and chemotaxis, the aggregation of platelets and the proliferation of SMCs [reviewed in 61]. As a result, the exercise-induced induction of eNOS may be responsible for a significant part of the antiinflammatory effects of exercise training in the vascular wall.

\section{PART III - EFFECT OF CHRONIC EXERCISE TRAINING ON INFLAMMATORY MARKERS OF ATHEROSCLERO- SIS}

In the latest reviews regarding the pathophysiology of atherosclerosis, matters such as vascular wall inflammation, chronic systemic low-grade inflammation and endothelial dysfunction seems to play very important roles. These three conditions are strictly linked one another. It is well known that the atherosclerotic plaque begins with a focal endothelial cell dysfunction [246,247]. This includes the overexpression of cellular adhesion molecules, which promote the recruitment of blood mononuclear cells, and the enhancement of the endothelial layer permeability, in turn facilitating the diffusion of low-density lipoproteins (LDL) to the intima [246,247]. Circulating leucocytes do not adhere to the healthy endothelium; but during lesion formation the endothelium expresses cell adhesion molecules (CAMs), including vascular cell adhesion molecule-1 (VCAM-1) and intercellular adhesion molecule-1 (ICAM-1), to which circulating leucocytes selectively attach [247, 248]. In the same way, chemoattractant stimuli originated in the vascular wall promote migration of leukocytes into the intima, where the macrophage colony-stimulating factor stimulates the differentiation of monocytes into macrophages [1,248]. The macrophages express scavenger receptors that allow them to engulf and modify oxidized lipoproteins and become foam cells [247,248]

This is the vascular event that promote the secretion of several number of inflammatory mediators, such as the cytokines, of which has been discussed previously in this paper. Progressive amplification of vascular inflammation can contribute to additional leukocyte accumulation, smooth muscle cell proliferation, and extracellular matrix remodelling [247,248]. This local inflammatory response sustained by primary pro-inflammatory cytokines (IL-1 and TNF- $\alpha$ ) further stimulates the production of IL-6 in several cell types, including smooth muscle cells and endothelial cells, which magnify the inflammatory response beyond the original focal area of endothelial dysfunction. Therefore, the increased circulating levels of IL-6 will further induce the hepatic synthesis of acute-phase proteins, including fibrinogen, CRP and serum amyloid A.

In this background, IL-6 acts as an amplifier of the acute-phase response, which is accountable for the augment of the expression/production of adhesion molecules, other cytokines, endothelin1 , endothelial plasminogen activator inhibitor-1, tissue factor in monocytes, LDL uptake by macrophages, and for the diminution of nitric oxide ( NO) bioavailability [249,250]. Simultaneously, the inflammatory response inhibits the production of collagen and stimulates macrophage expression of the potent procoagulant tissue factor, contributing to the prothrombotic blood environment nearby the areas of endothelial dysfunction [247,248]. Macrophage activity within the vascular wall may also contribute to plaque vulnerability and enhanced risk of plaque rupture, by elaborating matrix metalloproteinases which degrade the protective collagen structure of the plaque's fibrous cap, and consequently lead to the formation of thrombi that could lead to acute coronary events [247,248].

So, endothelial cell integrity is essential for preserving vascular homeostasis, allowing the continuous adjustment of vascular tone, the physiological regulation of leukocyte traffic, and the mainte- 
nance of blood fluidity [251]. In several pathological conditions, such as in atherosclerosis, the endothelial function is chronically disturbed in local areas. Endothelial dysfunction is characterized by an alteration in the basal endothelial phenotype (vasorelaxant, anticoagulant, antiplatelet and profibrinolytic), to one that is vasoconstrictive, procoagulant, platelet-activating, and antifibrinolytic $[252,253]$. The dysfunctional endothelial cells release lower levels of 'NO, prostacyclin, thrombomodulin and tissue plasminogen activator and meanwhile increase levels of endothelin-1, angiotensin II, plasminogen activator inhibitor (PAI)-1 and von Willebrand factor [254]. Tissue factor, which is not present on the functional endothelial cell surface, becomes expressed as a result of thrombin production. Thrombin is activated through the binding of activated factor $\mathrm{V}$ to activated factor $\mathrm{X}$ on the surface of the endothelial cell [252]. The utility of these molecules could be to serve as novel biomarkers of "endothelial health", whereby the effect of various therapeutic strategies could be monitored. Additionally, such strategies could be employed to explore the various mechanisms of exercise training upon the vascular endothelium in states of health and disease.

According to the current knowledge, regular exercise is a nonpharmacological therapeutic modality that enhances endothelial function in subjects with cardiovascular risk factors, including hypercholesterolemia [255], hypertension [29,256], metabolic syndrome [257], and type 2 diabetes mellitus [24,258], and in patients with established CAD [259,260] and heart failure [27,28,261]. In a prospective clinical study with CAD patients, 4 weeks of intensive exercise training decreased the coronary artery vasoconstriction, in response to acetylcholine, by 54\% [259]. Additionally, the followup of those patients indicated that the continuation of regular exercise, in a home-based program, could sustain, at least partially, the previously achieved effects on coronary endothelial function [261].

The augment of NO bioavailability induced by exercise could be the result of the increased activity/expression of eNOS, and/or the diminished degradation of $\mathrm{NO}$ in result to the reduced interaction with ROS Fig. (2). Studies using animal experiments [262,263] and cultured endothelial cells [264,265] suggested that shear stress increases eNOS expression/activity, probably due to the stabilization of eNOS mRNA [264] or the presence of transcription factors in the promoter region of eNOS gene enhancing the synthesis of mRNA [266]. Hambrecht et al., in 2003 [267], performed the first study demonstrating the positive effects of exercise training on vascular function and eNOS expression in the human vascular system. The authors found a 2-fold increase in eNOS mRNA expression and a 3.2 increase in the phosphorylation of eNOS on serine 1177 residue after 4 weeks of regular exercise training in CAD patients. This led to a rise in the enzymatic activity of eNOS and consequently to an enhanced $\mathrm{NO}$ production. Furthermore, regular exercise tends to increase the antioxidant defenses and by this way reduce the NO degradation [268]. This hypothesis was verified in heart failure patients in whom exercise improved NO-dependent vasodilatation without changes in eNOS expression. This was explained through the increase of antioxidant defences, such as the enhanced activity of Superoxide

Dismutase and Glutathione Peroxidase [269]. Moreover, in vitro studies showed that the application of laminar shear stress to cultured endothelial cells activates eNOS as well as the cytosolic copper/zinc containing Superoxide Dismutase pathway [270,271, $272,273]$. This increase in the antioxidant defences, observed both in myocardium and endothelial cells [271,272,273,274], seems to result from repetitive exposure to increased laminar shear stress during acute bouts of exercise training. The increase of antioxidant defences could also contribute to attenuating the formation of foam cells and vascular inflammation through the reduction of a crucial step in the atherogenesis: the LDL oxidation [275,276]. Indeed, the lipid oxidation, as the result of LDL exposure to the oxidative waste of intima layer, seems to be paramount to the foam cells formation, as native LDL is rapidly taken up by macrophages [247].
In summary, regular exercise promotes the acute increase of blood flow and shear stress and, in turn, improves the NO bioavailability, hence increasing the endothelium-dependent vasodilatation. This improvement could represent one of the most important mechanisms explaining the reduction of myocardial ischemia through regular exercise [259,267]. However, it should be noted that exercise intensity seems to be a crucial variable in this response. It is well established that moderate-intensity aerobic exercise augments endothelium-dependent vasodilatation in subjects with impaired endothelial function [277,278]. Nevertheless, recent studies in metabolic syndrome subjects [279] and heart failure patients [280] have shown that high intensity aerobic interval exercise was better than moderate-intensity aerobic exercise to increase endothelial function and NO availability. Wisløff et al. [280] suggested that the superior effect of aerobic interval training could be elicited by higher shear stress during the acute bouts of exercise, which triggers larger responses at the cellular and molecular level.

\section{Effects of Regular Physical Exercise on CRP and other In- flammatory Markers of Atherosclerosis}

An increasing number of studies have examined the antiinflammatory potential of chronic exercise through the assessment of circulating levels of several systemic markers of inflammation, first of all CRP (see Table 1). Nevertheless the discrepancies among the studies and the different behaviour of various classes of inflammatory markers in response to training, taken together the data from the main studies regarding this matter seem to indicate that exercise training might reduce the circulating levels of markers of inflammation.

The activation of the endothelial cell by cytokines, oxidized LDL, and ROS induce the endothelial expression of CAMs, such as ICAM-1, VCAM-1, E-selectin, and P-selectin, that are crucial to the recruitment of inflammatory cells to the vessel wall [281,282]. These molecules can be measured in circulation as soluble adhesion molecules since they are released in soluble form into the bloodstream from the proteolytic cleavage of membrane bound molecules.

Therefore, these molecules are considered to be important markers of endothelial cell activation and inflammation [282]. Exercise training seems to have a positive impact in the circulating CAMs. In subjects at risk of coronary events, two weeks of exercise training reduced circulating levels of soluble ICAM-1 [283]. Likewise, in heart failure patients, exercise training decreased the circulating levels of soluble ICAM-1, VCAM-1 [284], and P-selectin [285]. Also in animal experiments, exercise training performed 5 times per week for 6 to 8 weeks induced a significant decrease in the expression of P-selectin and VCAM-1 [286,287]. This positive impact of exercise on circulating CAMs could be related to changes in the transcriptional regulation of CAMs induced by shear stress [288]. Besides this direct influence in CAMs expression, exercise training might also have indirect favourable effects throughout the reduction of agonists of CAM synthesis, namely inflammatory cytokines [289], ROS [270,271], and, thus, the oxidation of LDL $[275,276]$. By reducing the soluble adhesion molecules, which may represent the interaction between activated monocytes/macrophages and endothelial cells, exercise training might be considered an effective non-pharmacological intervention to reduce endothelial adhesiveness.

Several prospective studies [289-294] examining the influence of exercise training alone or incorporated in more composite approaches associated to cardiac rehabilitation programs or other lifestyle interventions on markers of inflammation, have suggested an anti-inflammatory effect of chronic exercise (see Table 1). However, the majority of those studies are nonrandomized, uncontrolled, and observational.

Milani et al. [295,296] conducted the first studies assessing the effects of cardiac rehabilitation and exercise training on the plasma 
Table 1. Selected Studies that Examined the Effects of Exercise Training on Inflammatory Markers of Atherosclerosis

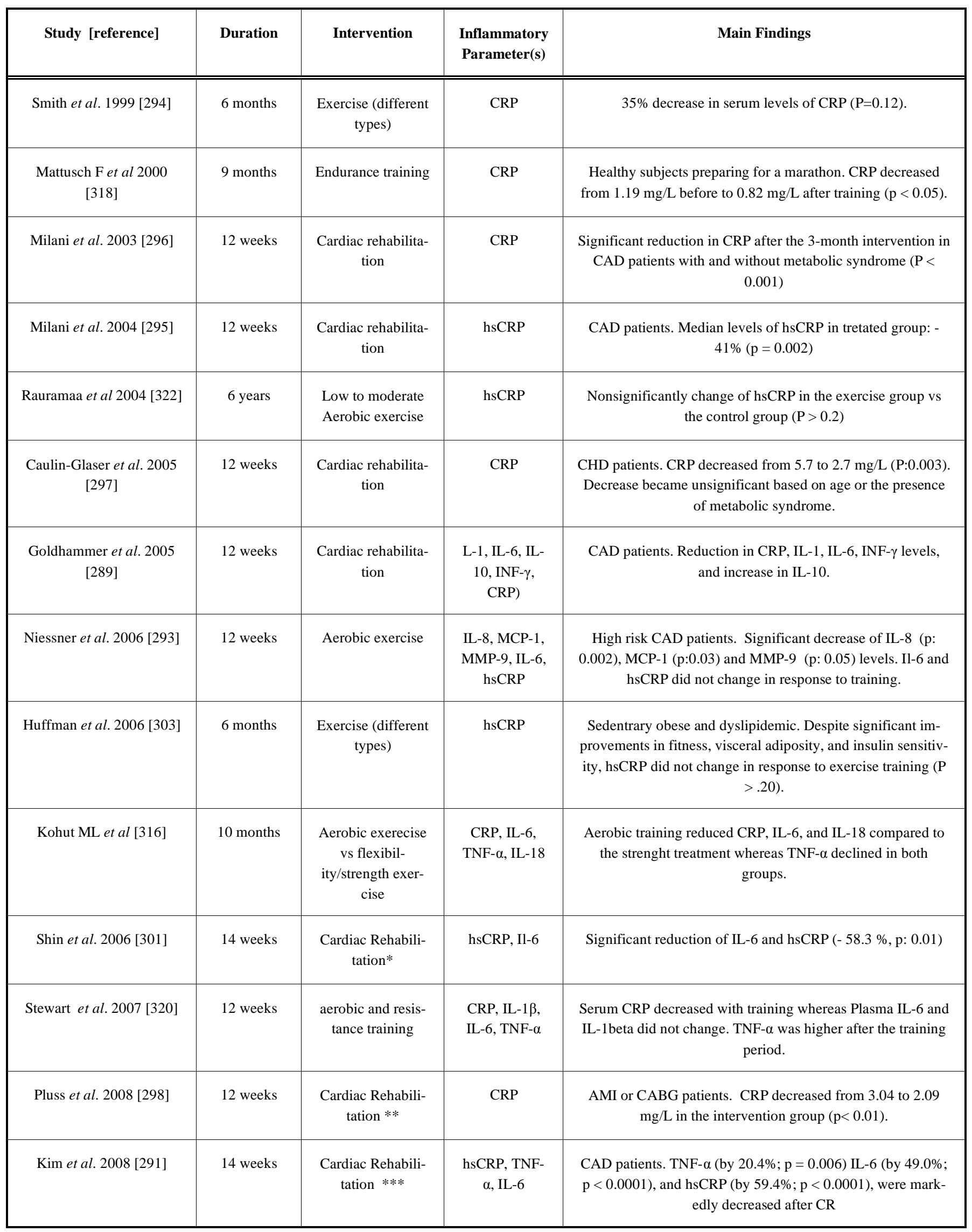


(Table 1) Contd....

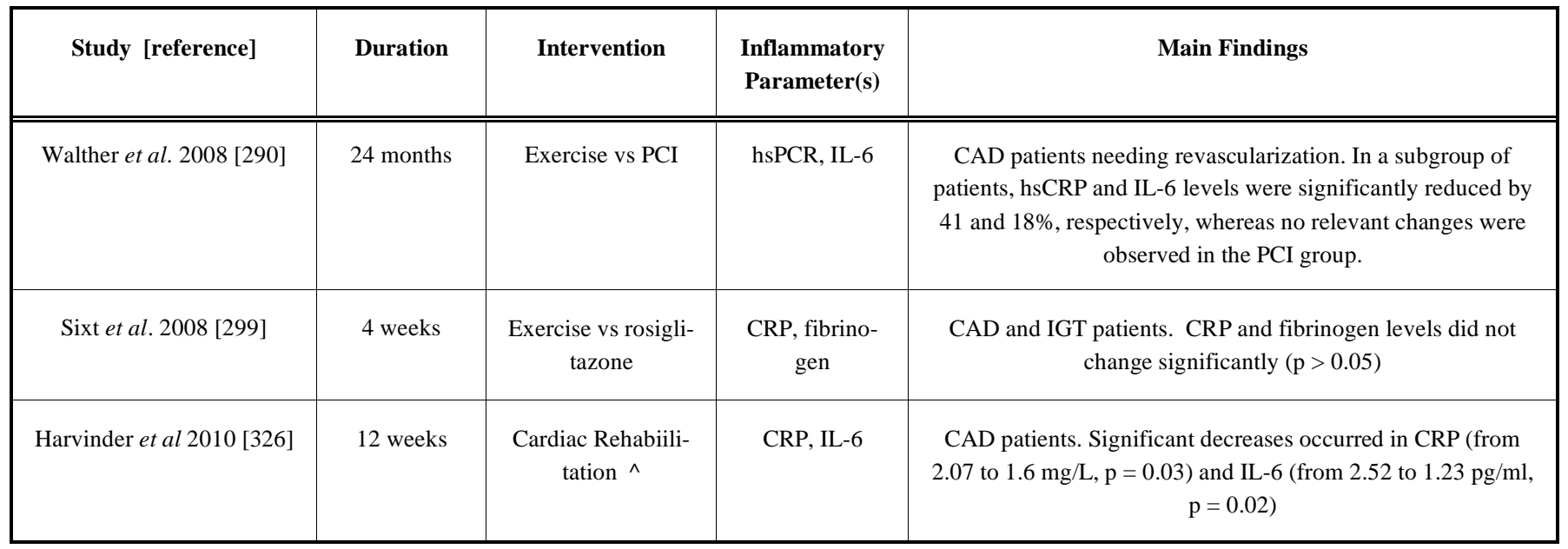

$\mathrm{CRP}$ = C-reactive protein; IL: Interleukin; PCI = percutaneous intervention; $\mathrm{CR}=$ cardiac rehabilitation; $\mathrm{CAD}=\mathrm{Coronary}$ Artery Disease; $\mathrm{CHD}=\mathrm{Coronary}$ Heart Disease; $\mathrm{MCP}-1$ = Monocyte chemoattractant protein-1; MMP: Metalloproteinase; AMI= Acute Myocardial Infarction; CABG= coronary artery by-pass grafting; IGT= Impaired glucose tolerance; * Cardiac Rehabilitation Therapy in this RCT consisted of a supervised 6 weeks of exercise following hospital discharge and 8 weeks of home stay exercise.

** "Expanded" Cardiac Rehabilitation in this RCT consisted of multifactorial interventions on metabolic and inflammatory markers, exercise performance and on established cardiovascular risk factors.

*** Cardiac Rehabilitation in this RCT consisted of 6 weeks supervised exercise training and 8 weeks home-based, self-managed exercise.

$\wedge$ the "Multisite Cardiac Lifestyle Intervention Program" performed in this trial consisted of change in diet (10\% calories from fat, plant based), engage in moderate exercise ( 3 hours/week), and practice stress management (1 hour/day).

levels of CRP. They found a significant reduction in CRP after the 3-month intervention in CAD patients with and without metabolic syndrome [296], in weight gainers and losers [295], and in patients with or without statin therapy [295]. This data was later confirmed by Caulin-Glaser et al. [297], who reported a consistent reduction of CRP in patients who showed no improvement or an increase in triglycerides, body mass index, and weight. Others [289,290,298] also observed the statins and weight loss-independent effects of exercise on CRP and other markers of inflammation. Goldhammer et al. [289], determining the effect of aerobic exercise training on levels of pro- and anti-inflammatory cytokines, IL-1, IL-6, IL-10, INF- $\gamma$, and CRP in CAD patients participating in a cardiac rehabilitation program found a significant reduction of CRP levels after 12 weeks of training. Cardiac training was associated with a $40.5 \%$ CRP reduction in enrolled patients compared to $19 \%$ reduction in non-diabetics ( $\mathrm{p}<0.01)$. Training resulted in a significant reduction of all pro-inflammatory cytokines, IL-1, $0.33 \pm 0.23$ to $0.51 \pm 0.12$ $\mathrm{pg} / \mathrm{ml}, \mathrm{p}=0.014$, IL- $6,2.50 \pm 1.50$ to $1.44 \pm 0.57 \mathrm{pg} / \mathrm{ml}, \mathrm{p}=0.002$, INF$\gamma, 18.63 \pm 3.31$ to $16.77 \pm 2.49 \mathrm{pg} / \mathrm{ml}, \mathrm{p}<0.001$, as well as a significant increase in the anti-inflammatory, cytokine IL-10, from $1.61 \pm 1.40$ to $2.29 \pm 2.01 \mathrm{pg} / \mathrm{ml}, \mathrm{p}=0.008$, obtaining an effective reduction of all the inflammatory markers [289].

In another interesting study, Walther et al. [290] randomized 101 patients with stable CAD but an indication for revascularization to either percutaneous intervention with stent or aerobic exercise training. In a subgroup of 66 patients, after 24 months of training, CRP levels were reduced by $41 \%$ and IL-6 levels by $18 \%$ whereas no change was observed in the percutaneous intervention group. The effects of exercise were independent of statin therapy. Therefore, this data suggests that cardiac rehabilitation and exercise training has an anti-inflammatory effect independent of statin therapy and weight loss.

As pointed out in the Table 1, the majority of evidence suggests that exercise training is related with ameliorations in biomarkers of systemic low-grade inflammation expressed by the circulating levels of CRP. However, not all the studies are univocal to confirm this relationship, infact two recent studies [299,300] failed to confirm this effect. This discrepancy may be due to a number of factors, including differences in subject characteristics and number, the timing of the blood samples taken, and the type, and the intensity and duration of the exercise intervention. Indeed, the duration of the intervention seems to be crucial, since the majority of studies showing improvements in the markers of inflammation included at least a 12-week exercise intervention. The two studies mentioned previously included 4 [299] and 7 [300] weeks of exercise training. It is interesting to note that levels of CRP showed a trend of decreasing following the 7 -week intervention. They decreased by $17.4 \%$, although without reaching statistical significance, suggesting that probably a longer intervention is needed to induce significant improvement in the inflammatory status of atherosclerotic patients, similarly to what occurred in other studies cited in Table 1, in which duration of intervention seem able to induce the obtaining of significance in CRP reduction [301,302,303].

Niessner et al. [293], evaluated effect of endurance training on atherosclerosis inflammatory markers in subjects with CAD and cardiovascular risk factors (CVRFs). In this study, after an intervention period of 12 weeks, authors found a significant decrease of the chemokines interleukin (IL)-8 (pre: $3.9 \pm 0.6$, change: $-1.2 \pm 0.4$ $\mathrm{pg} / \mathrm{ml},-21 \%, \mathrm{p}=0.002$ ) and monocyte chemoattractant protein-1 (pre: $213 \pm 9$, change: $-20.4 \pm 8.2 \mathrm{pg} / \mathrm{ml},-5 \%, \mathrm{p}=0.03$ ) and of matrix metalloproteinase-9 (MMP-9), that highly significantly decreased in response to training (pre: $750+/-98$, change: $-278+/-77$ $\mathrm{ng} / \mathrm{ml},-18 \%, \mathrm{p}=0.005$ ), but a unsignificant change of IL-6 (pre: $1.7+/-0.3$, change: $+0.25+/-0.7 \mathrm{pg} / \mathrm{ml},+4 \%, \mathrm{p}=0.58)$ and hsCRP (pre: $2.1+/-0.5$, change: $-0.25+/-0.4 \mathrm{mg} / 1,-9 \%, \mathrm{p}=0.54$ ) (see Table 1) and [293]; rather low levels of acute phase reactants with high relative intraindividual variations may have limited the ability to find a significant change with the sample size of this cohort.

Kasapis et al. [304] in their paper underline the inverse relationship existing between serum CRP levels and both physical activity level and cardiorespiratory fitness, finding out several emerging potential mechanisms to enlighten the CRP decrease induced by exercise training alone or as a core component of a cardiac rehabilitation program, all of them closely related to the decrease of cytokine production, namely IL- 6 , IL-1, and TNF- $\alpha$ [304]. These associations remain after controlling for potential confounders in some studies [305,306,307], although other authors suggest that may be 
influenced by factors, such as gender, body composition and the type of physical activity.

The relationship between obesity and CRP levels, was particularly analyzed. The effect of physical exercise of reduction of obesity, particularly central obesity, with a consequent decrease in the adipocyte production of inflammatory cytokines, seems infact to be a confounding factor for explaining CRP reduction levels after physical exercise. It is well documented that obesity, especially central obesity, is associated with CRP levels [305,306], possibly due to the increased production of the inflammatory cytokines IL-6 and TNF- $\alpha$, by the adipocyte [308]. Accordingly, exercise could mitigate inflammation by reducing body weight.

In NHANES III (Third National Health and Nutrition Examination Survey III [309]), jogging and aerobic dancing were associated with lower CRP levels when compared with other forms of activity, including swimming, cycling and weightlifting. In this study [309], involving 13,748 US adults age 20 years or older, time devoted to physical activity is inversely associated with CRP, fibrinogen concentrations, and white blood cell count. In particular, after adjusting for several confounding factors, the risk reduction for elevated CRP concentrations (dichotomized at the $\geq 85$ th percentile of the sexspecific distribution) were $2 \%, 15 \%$, and $47 \%$ for participants who engaged in light, moderate, and vigorous physical activity, respectively. In another study of the Third National Health and Nutrition Examination Survey, Abramson and Vaccarino [310] reported that of 3638 healthy US men and women age 40 years and older studied, a graded reduction in elevated CRP levels resulted from the number of times the participants engaged in physical exercise. The reduction in the risk of those engaging in physical activity 4-21 times per month was $23 \%$, while the reduction of those engaging 22 or more times per month was $47 \%$. Similar associations were seen for white blood cell count and fibrinogen levels.

Several observational studies indicate that chronic physical activity reduces CRP levels more in males than females [311,312], and no relationship between physical activity levels and CRP is found in some studies after adjusting for BMI (body mass index) and other risk factors [313,314]. However, exercise training decreased the circulating levels of Il-6, Il-1, and CRP levels by $48 \%$ independent of changes in body weight or body mass index [289]. Likewise, exercise training also reduced the levels of CRP in CAD patients who experience weight gain [297] or who experienced no changes in body fat [295], suggesting that other factors could contribute to the exercise-related anti-inflammatory effect. The decreased production of cytokines in others sites beyond adipose tissue, such as skeletal muscle and mononuclear cells could be pointed out as another possible mechanism mediating the anti-inflammatory effect of exercise.

A meta-analysis of RCTs (randomized controlled clinical trials) published recently concluded that aerobic exercise training does not reduce basal CRP levels [315]. This meta-analysis included data from 323 subjects in five separate trials in which subjects were randomized to either a control group or an aerobic exercise intervention lasting at least 8 weeks. Overall, there was a $3 \%$ reduction in CRP levels in the exercise groups, but this change was not statistically significant.

An interesting work by Kohut et al. [316], not reported in the previously cited meta-analysis, being published afterwards, compared effects of aerobic exercise treatment and flexibility/strength exercise treatment performed 3 days/week, $45 \mathrm{~min} /$ day for 10 months. Authors found that aerobic exercise, but not flexibility and resistance exercise, significantly reduced serum CRP, L-6, and IL18 compared to the strength/flexibility treatment (significant treatment $\mathrm{x}$ time interaction, $\mathrm{p}<.05$ ), whereas TNF-alpha declined in both groups (main effect of time, $p=.001$ ) [316].

In a recent paper by Plaisance and Grandjean [317], the authors reviewed data from a number of longitudinal studies and concluded that long-term exercise training significantly reduces CRP levels, and that this effect may be independent of baseline CRP levels, body composition and weight loss. However, none of the studies reviewed were RCTs. In the only study with a control group, CRP was reduced from 1.19 to $0.82 \mathrm{mg} / 1(31 \%)$ in highly trained runners after 9 months of increased training in preparation for a marathon, but did not change significantly in non-training control subjects [318]. Although the reduction in CRP in the training group in this study was statistically significant, the physiological relevance of such a small absolute change in CRP levels is unknown. Furthermore, because the subjects in the 'training' group were already highly fit runners, the significance of these findings to the population at large is also uncertain.

Additional RCTs assessing the effects of exercise training on CRP levels are clearly needed. Most of the studies conducted to date have included interventions of 4 months or less, many have included subjects with relatively low baseline CRP levels and almost none have not controlled for statin use. In addition, it is uncertain whether exercise has a direct effect on CRP levels independent of weight loss. Weight loss has consistently been shown to reduce CRP levels [319]. Most exercise training interventions have shown modest or no effects on CRP after statistically correcting for weight loss, but few studies have assessed the effect of different types of exercise on CRP in the absence of weight loss [319,320,321]. Longer-term studies controlling for these factors are needed before any significant conclusions can be drawn regarding the impact of regular exercise on serum CRP levels. Probably on of the longer study available is the DNASCO (DNA Polymorphism and Carotid Atherosclerosis) Study [322], a 6-year randomized, controlled trial in a population-based sample of middle-aged men, we investigated the effect of regular long-term physical exercise on chronic lowgrade inflammation and the progression of atherosclerosis. In this study High-sensitivity CRP levels were statistically nonsignificantly lower in the exercise group than in the control group after 6 years of aerobic training, and also the progression of intima-media thickness in the carotid artery did not differ between the study groups $(P>0.2)$. The study was probably underpowered to detect changes in high-sensitivity CRP level, confirming how in future larger studies, sex, age, dose response, and exercise methods should be addressed, to study for longer periods the interactions of regular exercise and atherosclerotic inflammation markers.

Geffken et al. [323], reported consistent findings in the Cardiovascular Health Study cohort of 5888 men and women. Compared with those in the lowest quartile of self-reported physical activity, those in the highest quartile had $19 \%, 6 \%, 4 \%$, and $3 \%$ lower concentrations of CRP, white blood cells, fibrinogen, and factor VIII activity, respectively, after adjustment for gender, presence of CVD, age, race, smoking, body mass index (BMI), diabetes, and hypertension. It was also suggested by the same investigators [323] that the association of higher levels of physical activity with lower levels of inflammation markers may be mediated by BMI and glucose. Further support for the latter hypothesis is provided by a report on the association between BMI and CRP, IL-6, and soluble tumor necrosis factor receptors (sTNF-Rs) 1 and 2. [324], Further biomarkers were measured in 405 healthy men and 454 healthy women from two large ongoing prospective studies.

After adjustment for other predictors of inflammation, physical activity was inversely associated with plasma levels of sTNF-R1, sTNF-R2, IL-6, and CRP ( $\mathrm{p}=0.07, \mathrm{p}=0.004, \mathrm{p}=0.04$, and $\mathrm{p}=0.009$, respectively). After further adjustment for BMI and leptin, most of these associations were insignificant surrogates for fat mass [324].

These study confirm the previous data reported in which has been addressed the hypothesis that obesity not only can interfere with achieving the level of physical activity necessary for cardiovascular health but also, therefore, could represent an independent factor affecting inflammatory markers and interfering with physical activity. Other interference between adipokynes, myokines, cardio- 
vascular and systemic effects of chronic exercise and inflammatory markers of atherosclerosis cannot be excluded.

In a study by Reuben et al., [325], 870 persons aged 70-79 years in the top $33 \%$ of community-dwelling older persons with respect to physical and cognitive functioning observed an association between high levels of recreational activity and lower levels of the inflammatory markers, i.e., IL-6 and CRP. Their findings suggest a mechanism for the protective effect of physical activity and support interventions that increase physical activity in older persons in order also to prevent progression of subclinical atherosclerosis .

Although not directly related to atherosclerosis the previously cited work by Mattusch et al. [318] provide further interesting data. The authors measured CRP serum levels before and after 9 months of training in 14 subjects preparing for a marathon, studying the outcome effect of training on the baseline CRP concentration. Although training intensity was continuously increased, baseline CRP diminished in 10 of the 12 runners. The CRP median fell from 1.19 $\mathrm{mg} / \mathrm{L}$ before training to $0.82 \mathrm{mg} / \mathrm{L}$ after training $(\mathrm{p}<0.05)$. Since we stressed the concept of paradox pro-inflammatory effects of acute intense physical activity, it is interesting report that after strenuous repeated aerobic exercise bouts the CRP basal levels decreased. The decrease of CRP concentration after intense regular training suggests that also intensive regular exercise has a systemic antiinflammatory effect, contrary to the effect on muscles and tendons. These informations should probably be usefully assimilated in protocols dedicated to cardiologic rehabilitation, testing stronger exercise protocols in order to evaluate if can be reached more ambitious reduction target of the inflammatory markers.

The various experimental models only partly justify the heterogeneous results showed before; certainly different types of training interventions are obvious reasons for discrepancies, e.g., endurance training versus resistance training; differences in the intensity of exercise and/or time duration of the single bout of exercise, as well as the full duration of the intervention program. Discrepancies may be found not only in the trials that have addressed the issue regarding the potentiality of regular exercise training to reduce serum CRP level, but also studies examining the effects of chronic exercise on cytokine production and circulating cytokine levels have been somewhat conflicting.

Cross-sectional studies indicate that increasing levels of physical activity and/or fitness are generally associated with modest reductions in circulating levels of TNF- $\alpha$ and IL-6, and increased levels of IL-10 [53,289,293]. Consistent with this, Smith et al. [294] observed a 58\% reduction in the production of the proinflammatory cytokines IFN- $\gamma$ (interferon- $\gamma$ ), TNF- $\alpha$ and IL- $1 \beta$, and a $36 \%$ increase in the production of the anti-inflammatory cytokines TGF- $\beta$ (transforming growth factor- $\beta$ ), IL-4 and IL-10, by cultured mononuclear cells from individuals at risk of developing ischemic heart disease following 6 months of exercise training compared with baseline levels. In addition, some studies demonstrate reduced circulating levels of TNF- $\alpha$, IL- 6 , IFN- $\gamma$ and other markers of systemic inflammation following exercise training, although several others do not (reviewed in [294]). These changes in cellular function were reflected in the serum levels of CRP, which decreased by $35 \%$, although without reaching statistical significance. These discrepancies may be due to a number of factors, including differences in subject characteristics, the type and intensity of the exercise intervention, the timing of the blood samples taken and inherent variability in the assays used to measure many of these cytokines. Nevertheless, the preponderance of evidence suggests that both acute and chronic exercise is associated with modest improvements in markers of systemic low-grade inflammation.

Also in patients with heart failure, six months of exercise training reduced the skeletal muscle TNF- $\alpha$, IL-1-beta and Il- 6 expression. However the serum levels of the above mentioned parameters remained unaffected [138], raising the question of whether this local change has physiological repercussions at a systemic level. The enhancement of endothelial function could be another option to justify the decrease of inflammatory status by exercise training, through the reduction of IL-1 and IL- 6 released by the endothelium. In fact, several studies have provided evidence supporting the positive impact of exercise training on endothelial function; as earlier explained, exercise training improves $\mathrm{NO}$ bioavailability [267] and reduces circulating markers associated with endothelial dysfunction [284,285]. Finally, the favourable impact of exercise training on biomarkers of inflammation could be related to the diminishment of oxidative stress and LDL oxidation, hence reducing monocyte activation and, in this way, attenuating the production of inflammatory cytokines. Indeed, exercise training reduces oxidative stress in skeletal muscle [327] and in the vasculature [268], and reduces the level of circulating markers of oxidative stress [328].

As previously underlined, TNF- $\alpha$ levels don not increase after acute exercise [51,53]. Effects of chronic exercise on basal TNF- $\alpha$ levels have been evaluated by Starkie et al. [73], performed three experiments in which healthy young men rested for $3 \mathrm{~h}$ (control), rode a bicycle for $3 \mathrm{~h}$, and were infused with rIL-6 for $3 \mathrm{~h}$. After $21 / 2 \mathrm{~h}$, subjects received a bolus of Escherichia coli endotoxin in all experiments. This resulted in a twofold increase in circulating TNF$\alpha$ in the control experiment, whereas the response was totally attenuated in relation to exercise or rIL-6 administration. This experiment supports the hypothesis that physical activity mediates strong anti-inflammatory effects also against this main proinflammatory cytokine; an effect reasonable mediated by the muscular production of IL- 6 and the other anti-inflammatory myokines able to interfere with immunologic asset of the organism, as underlined before in this paper. Nevertheless of this, a modest decrease in TNF- $\alpha$ was also observed in IL- $6 \mathrm{KO}$ mice, suggesting the existence of anti-inflammatory exercise effects mediated via IL-6 and an IL-6-independent mechanism [329]. In accordance with experimental observations, TNF- $\alpha$ mRNA in skeletal muscle declined in relation to a training intervention in patients with chronic heart failure, whereas a decline in systemic low-level inflammation was not detected [138].

However, TNF- $\alpha$ mRNA was not reduced in skeletal muscle after 8 weeks of bicycle exercise in obese adults [330].

\section{CONCLUSIONS}

Atherosclerosis, and, in particular, its acute complications, is a major cause of mortality and morbidity around the world and is likely to continue to increase as a cause of death. Prevention and treatment of cardiovascular disease is still a clinical challenge. Several lines of research have converged to suggest that the biology of the plaque is the real 'culprit' of clinical manifestations of atherosclerosis.

Inflammatory signaling pathways are implicated in early atherogenesis, in the progression of lesions and finally in the acute complications of the disease. The recent identification of skeletal muscle as an endocrine organ that produces and releases myokines expands our knowledge on how the nervous, endocrine, and immune systems contribute to the maintenance of homeostasis, especially when energy demands are increased. Since in the 1990s the discovery of adipose tissue as a secretory organ dominate the researchs in this area, the finding that muscles produce and release cytokines (myokines) suggests that in addition to adipose tissue working skeletal muscle may be a major source of secreted molecules.

Myokines may be involved in mediating the health beneficial effects of exercise and play important roles in the protection against diseases associated with chronic low-grade inflammation, such as insulin resistance, type 2 diabetes, cancer and, naturally, cardiovascular atherosclerotic disease. Given that atherosclerotic process is characterized in all its phases by inflammation, many theoretical benefits could be provided by regular exercise, although further 
scientific validations about the improvement on atherosclerosis progression, about the outcome benefit of atherosclerotic patient and finally about regression of low-grade inflammation and relationship between myokines and systemic inflammatory mediators of atherosclerosis are needed.

It is obvious that knowledge about the mechanisms whereby regular exercise offers protection against chronic diseases in combination with clinical research serves as a foundation for the development of public health guidelines with regard to exercise. Moreover, more specific knowledge about the mechanisms whereby exercise alters the function and metabolism in other organs, such as adipose tissue, liver, and brain, is required to prescribe exercise as therapy in the form of endurance training, metabolic training, or strength conditioning, since different types of exercise provide different degree of variations of systemic inflammation through different myokinic muscular response.

Finally, it is obvious that the identification of new myokines and their receptors will potentially serve as pharmacological targets for the prevention and treatment of atherosclerotic disease, metabolic disorders and other chronic diseases.

Nevertheless discrepancies, analysis of available researches seem to confirm the efficacy of regular physical training as a nonpharmacological therapy having target chronic low-grade inflammation. Given this, physical exercise could be considerate a useful weapon against local vascular and systemic inflammation in atherosclerosis. Several mechanisms explain the positive effect of chronic exercise, nevertheless, these mechanisms do not fully enlighten all pathways by which exercise can decrease inflammation and endothelial dysfunction, and hence modulate the progression of the underlying disease progress. Future research is needed to provide convincing support to the mechanisms explaining the beneficial effect of exercise in the inflammatory profile of atherosclerotic patients.

\section{CONFLICT OF INTEREST}

The authors confirm that this article content has no conflicts of interest.

\section{ACKNOWLEDGEMENT}

None declared.

\section{REFERENCES}

[1] Ross R. Atherosclerosis--an inflammatory disease. N Engl J Med 1999; 340(2): 115-26.

[2] Ross R, Harker L. Hyperlipidemia and atherosclerosis. Science 1976; 193: 1094-100.

[3] Libby P. Inflammation in atherosclerosis. Nature 2002; 420: 868874.

[4] Libby P, Ridker PM, Maseri A. Inflammation and atherosclerosis. Circulation 2002; 105: 1135-43

[5] Dandona P, Aljada A, Bandyopadhyay A. Inflammation: the link between insulin resistance, obesity and diabetes. Trends Immunol 2004; $25: 4-7$.

[6] Landi S, Moreno V, Gioia-Patricola L, et al. Association of common polymorphisms in inflammatory genes interleukin (IL)6, IL8, tumor necrosis factor $\alpha$, NFKB1, and peroxisome proliferatoractivated receptor $\gamma$ with colorectal cancer. Cancer Res 2003; 63: 3560-6.

[7] Hallenbeck JM. The many faces of tumor necrosis factor in stroke. Nat Med 2002; 8: 1363-8.

[8] Gan WQ, Man SF, Senthilselvan A, Sin DD. Association between chronic obstructive pulmonary disease and systemic inflammation: a systematic review and meta-analysis. Thorax 2004; 59: 574-80.

[9] Akiyama H, Barger S, Barnum S, et al. Inflammation and Alzheimer's disease. Neurobiol. Aging 2000; 21: 383-421.

[10] Mohamed-Ali V, Goodrick S, Rawesh A, et al. Subcutaneous adipose tissue releases interleukin-6, but not tumor necrosis factoralpha, in vivo. J Clin Endocrinol Metab 1997; 82: 4196-200.

[11] Kershaw EE, Flier JS. Adipose tissue as an endocrine organ. J Clin Endocrinol Metab 2004; 89: 2548-56.
[12] Pedersen BK, Febbraio MA. Muscle as an endocrin organ: focus on muscle-derived Interleukin-6. Physiol Rev 2008; 88: 1379-406.

[13] Ridker PM, Hennekens CH, Buring JE, Rifai N. C-reactive protein and other markers of inflammation in the prediction of cardiovascular disease in women. N Engl J Med 2000; 342: 836-43.

[14] Di Francia M, Barbier D, Mege JL, Orehek J. Tumor necrosis factor- $\alpha$ levels and weight loss in chronic obstructive pulmonary disease. Am J Respir Crit Care Med 1994; 150: 1453-5.

[15] Ferrucci L, Penninx BW, Volpato S, et al. Change in muscle strength explains accelerated decline of physical function in older women with high interleukin-6 serum levels. J Am Geriatr Soc 2002; 50: 1947-54

[16] Barzilay JI, Abraham L, Heckbert SR, et al. The relation of markers of inflammation to the development of glucose disorders in the elderly: the Cardiovascular Health Study. Diabetes 2001; 50: 23849.

[17] Freeman DJ, Norrie J, Caslake MJ, et al. C-reactive protein is an independent predictor of risk for the development of diabetes in the West of Scotland Coronary Prevention Study. Diabetes 2002; 51: 1596-600.

[18] Lindsay RS, Funahashi T, Hanson RL, et al. Adiponectin and development of type 2 diabetes in the Pima Indian population. Lancet 2002; 360: 57-8

[19] Volpato S, Guralnik JM, Ferrucci L, et al. Cardiovascular disease, interleukin-6, and risk of mortality in older women: the women's health and aging study. Circulation 2001; 103: 947-53.

[20] Li JJ, Fang CH. C-reactive protein is not only an inflammatory marker but also a direct cause of cardiovascular diseases. Med. Hypotheses 2004; 62: 499-506

[21] Blair SN, Cheng Y, and Holder JS. Is physical activity or physical fitness more important in defining health benefits? Med Sci Sports Exerc 2001; 33: S379-99.

[22] Jolliffe JA, Rees K, Taylor RS, Thompson D, Oldridge N, Ebrahim S. Exercise-based rehabilitation for coronary heart disease. Cochrane Database Syst Rev 2000; 4: CD001800.

[23] Piepoli MF, Davos C, Francis DP, Coats AJ. Exercise training meta-analysis of trials in patients with chronic heart failure (ExTraMATCH). BMJ 2004; 328: 189-95.

[24] Boule NG, Haddad E, Kenny GP, Wells GA, Sigal RJ. Effects of exercise on glycemic control and body mass in type 2 diabetes mellitus: a meta-analysis of controlled clinical trials. JAMA 2001; 286: 1218-27.

[25] Lacasse Y, Brosseau L, Milne S, et al. Pulmonary rehabilitation for chronic obstructive pulmonary disease. Cochrane Database Syst Rev 2002; 3: CD003793.

[26] Taylor RS, Brown A, Ebrahim S, et al. Exercise-based rehabilitation for patients with coronary heart disease: systematic review and meta-analysis of randomized controlled trials. Am J Med 2004; 116(10): 682-92

[27] Gielen S, Schuler G, Hambrecht R. Exercise training in coronary artery disease and coronary vasomotion. Circulation 2001; 103(1): E1-6.

[28] Bensimhon DR, Adams GL, Whellan DJ, Pagnanelli RA, Trimble $\mathrm{M}$, Lee BA. Effect of exercise training on ventricular function, dyssynchrony, resting myocardial perfusion, and clinical outcomes in patients with heart failure: a nuclear ancillary study of Heart Failure and A Controlled Trial Investigating Outcomes of Exercise TraiNing (HF-ACTION). Am Heart J 2007; 154(1): 46-53.

[29] Pinto A, Di Raimondo D, Tuttolomondo A, Fernandez P, Arnao V, Licata G. Twenty-four hour ambulatory blood pressure monitoring to evaluate effects on blood pressure of physical activity in hypertensive patients. Clin J Sport Med 2006 May; 16(3): 238-43.

[30] Glass CK, Witzym JL. Atherosclerosis: the road ahead. Cell 2001; 104: 503-516.

[31] Nordestgaard BG, Nielsen LB. Atherosclerosis and arterial influx of lipoproteins. Curr Opin Lipidol, 1994; 5: 252-7.

[32] Williams KJ, Tabas I. The response-to-retention hypothesis of atherogenesis reinforced. Curr Opin Lipidol 1998; 9: 471-74.

[33] Branen L, Hovgaard L, Nitulescu M, Bengtsson E, Nilsson J, Jovinge $S$. Inhibition of tumor necrosis factor- $\alpha$ reduces atherosclerosis in apolipoprotein E knockout mice. Arterioscler Thromb Vasc Biol 2004; 24: 2137-42.

[34] Ridker PM. High-sensitivity C-reactive protein: potential adjunct for global risk assessment in the primary prevention of cardiovascular disease. Circulation 2001; 103: 1813-8. 
[35] Ridker PM, Wilson PW, Grundy SM. Should C-reactive protein be added to metabolic syndrome and to assessment of global cardiovascular risk? Circulation 2004; 109: 2818-25.

[36] Dinarello CA. Interleukin 1 and interleukin 1 antagonism. Blood 1991; 77: 1627-52.

[37] Esposito K, Marfella R, Ciotola M, et al. Effect of a mediterraneanstyle diet on endothelial dysfunction and markers of vascular inflammation in the metabolic syndrome: a randomized trial. JAMA 2004; 292: 1440-6.

[38] Pedersen M, Bruunsgaard $\mathrm{H}$, Weis N, et al. Circulating levels of TNFalpha and IL-6-relation to truncal fat mass and muscle mass in healthy elderly individuals and in patients with type-2 diabetes. Mech Ageing Dev 2003; 124: 495-502.

[39] Willerson JT, Ridker PM. Inflammation as a cardiovascular risk factor. Circulation 2004; 109: II2-10.

[40] Bruunsgaard H, Andersen-Ranberg K, Jeune B, Pedersen AN, Skinhoj P, Pedersen BK. A high plasma concentration of TNFalpha is associated with dementia in centenarians. J Gerontol A Biol Sci Med Sci 1999; 54: M357-64.

[41] Bruunsgaard H, Skinhoj P, Pedersen AN, Schroll M, Pedersen BK. Ageing, tumour necrosis factor-alpha (TNF-alpha) and atherosclerosis. Clin Exp Immunol 2000; 121: 255-60

[42] Tedgui A, Mallat Z. Cytokines in atherosclerosis: pathogenic and regulatory pathways. Physiol Rew 2006; 86: 515-81.

[43] Vgontzas AN, Papanicolaou DA, Bixler EO, Hopper K, Lotsikas A, Lin HM. Sleep apnea and daytime sleepiness and fatigue: relation to visceral obesity, insulin resistance, and hypercytokinemia. J Clin Endocrinol Metab 2000; 85: 1151-1158.

[44] Volpato S, Guralnik JM, Ferrucci L, et al. Cardiovascular disease, interleukin-6, and risk of mortality in older women: the women's health and aging study. Circulation 2001; 103: 947-53.

[45] Ridker PM, Rifai N, Stampfer MJ, Hennekens CH. Plasma concentration of interleukin- 6 and the risk of future myocardial infarction among apparently healthy men. Circulation 2000; 101: 1767-72.

[46] Ridker PM, Rifai N, Rose L, Buring JE, Cook NR. Comparison of $\mathrm{C}$-reactive protein and low-density lipoprotein cholesterol levels in the prediction of first cardiovascular events. N Engl J Med 2002; 347: 1557-65.

[47] Terry CF, Loukaci V, Green FR. Cooperative influence of genetic polymorphisms on interleukin 6 transcriptional regulation. J Biol Chem 2000; 275: 18138-44.

[48] Bruunsgaard H, Christiansen L, Pedersen AN, Schroll M, Jorgensen T, Pedersen BK. The IL-6 -174C polymorphism is associated with cardiovascular diseases and mortality in 80-year-old humans. Exp Gerontol 2004; 39: 255-61.

[49] Wilson AG, Symons JA, McDowell TL, McDevitt HO, Duff GW. Effects of a polymorphism in the human tumor necrosis factor alpha promoter on transcriptional activation. Proc Natl Acad Sci USA 1997; 94: 3195-9.

[50] Kubaszek A, Pihlajamaki J, Komarovski V, et al. Promoter polymorphisms of the TNF-alpha (G-308A) and IL-6 (C-174G) genes predict the conversion from impaired glucose tolerance to type 2 diabetes: the Finnish Diabetes Prevention Study. Diabetes , 2003; 52: $1872-6$.

[51] Petersen AMW, Pedersen BK. The anti-inflammatory effect of exercise. J Appl Physiol 2005; 98: 1154-62

[52] McDermott MF. TNF and TNFR biology in health and disease. Cell Mol Biol (Noisy-le-grand) 2001; 47: 619-35.

[53] Bruunsgaard H. Physical activity and modulation of systemic lowlevel inflammation. J Leukocyte Biol 2005; 78: 819-35.

[54] Skoog T, Dichtl W, Boquist S, et al. Plasma tumour necrosis factor- $\alpha$ and early carotid atherosclerosis in healthy middle-aged men. Eur. Heart J 2002; 23: 376-83.

[55] Rus HG, Niculescu F, Vlaicu R. Tumor necrosis factor- $\alpha$ in human arterial wall with atherosclerosis. Atherosclerosis 1991; 89: 247-54.

[56] Meager A. Cytokine regulation of cellular adhesion molecule expression in inflammation. Cytokine Growth Factor Rev 1999; 19: 27-39.

[57] Rectenwald JE, Moldawer LL, Huber TS, Seeger JM, Ozaki CK. Direct evidence for cytokine involvement in neointimal hyperplasia. Circulation 2000; 102: 1697-1702.

[58] Bhagat K, Vallance P. Inflammatory cytokines impair endothelium- dependent dilatation in human veins in vivo. Circulation 1997; 96: 3042-7.
[59] Schreyer SA, Vick CM, LeBoeuf RC. Loss of lymphotoxin-alpha but not tumor necrosis factor-alpha reduces atherosclerosis in mice. J Biol Chem 2002; 277: 12364 -8.

[60] Branen L, Hovgaard L, Nitulescu M, Bengtsson E, Nilsson J, Jovinge S. Inhibition of Tumor Necrosis Factor-alpha Reduces Atherosclerosis in Apolipoprotein E Knockout Mice. Arterioscler Thromb Vasc Biol 2004; 24(11): 2137-42.

[61] De Winther PJ, Kanters E, Kraal G, Hofker MH. Nuclear factor kB signaling in atherogenesis. Arterioscler Thromb Vasc Biol 2005; 25: 904-14

[62] Kirii H, Niwa T, Yamada Y, et al. Lack of interleukin-1beta decreases the severity of atherosclerosis in ApoE-deficient mice. Arterioscler Thromb Vasc Biol 2003; 23: 656-60.

[63] Chi H, Messas E, Levine RA, Graves DT, Amar S. Interleukin-1 receptor signaling mediates atherosclerosis associated with bacterial exposure and/or a high-fat diet in a murine apolipoprotein $\mathrm{E}$ heterozygote model: pharmacotherapeutic implications. Circulation 2004; 110 : $1678-85$.

[64] Akira S, Taga T, Kishimoto T. Interleukin-6 in biology and medicine. Adv Immunol 1993; 54: 1-78.

[65] Woods A, Brull DJ, Humphries SE, Montgomery HE. Genetics of inflammation and risk of coronary artery disease: the central role of interleukin-6. Eur Heart J 2000; 21: 1574-83.

[66] Ershler WB. Interleukin-6: a cytokine for gerontologists. J Am Geriatr Soc 1993; 41: 176-81.

[67] Biasucci LM, Vitelli A, Liuzzo G, Altamura et al. Elevated levels of interleukin-6 in unstable angina. Circulation 1996; 94: 874-7.

[68] Harris TB, Ferrucci L, Tracy RP, et al. Associations of elevated interleukin-6 and C-reactive protein levels with mortality in the elderly. Am J Med 1999; 106: 506-12.

[69] Yudkin JS, Kumari M, Humphries SE, Mohamed-Ali V. Inflammation, obesity, stress and coronary heart disease: is interleukin-6 the link? Atherosclerosis 2000; 148: 209-14.

[70] Elhage R, Clamens S, Besnard S, et al. Involvement of interleukin6 in atherosclerosis but not in the prevention of fatty streak formation by 17 beta-estradiol in apolipoprotein E-deficient mice. Atherosclerosis 2001; 156: 315-20.

[71] Xing Z, Gauldie J, Cox G, et al. IL-6 is an antiinflammatory cytokine required for controlling local or systemic acute inflammatory responses. J Clin Invest 1998; 101: 311-320.

[72] Huber SA, Sakkinen P, Conze D, Hardin N, Tracy R. Interleukin-6 exacerbates early atherosclerosis in mice. Arterioscler Thromb Vasc Biol 1999; 19: 2364 -7.

[73] Starkie R, Ostrowski SR, Jauffred S, Febbraio M, Pedersen BK. Exercise and IL-6 infusion inhibit endotoxin-induced TNF- $\alpha$ production in humans. FASEB J 2003; 17: 884-6.

[74] Van Lenten BJ, Wagner AC, Navab M, Fogelman AM. Oxidized phospholipids induce changes in hepatic paraoxonase and ApoJ but not monocyte chemoattractant protein-1 via interleukin-6. J Biol Chem 2001; 276: 1923-9.

[75] Schieffer B, Selle T, Hilfiker A, et al. Impact of interleukin-6 on plaque development and morphology in experimental atherosclerosis. Circulation 2004; 110: 3493-500.

[76] Song L, Schindler C. IL-6 and the acute phase response in murine atherosclerosis. Atherosclerosis 2004; 177: 43-51.

[77] Choy EH, Isenberg DA, Garrood T, et al. Therapeutic benefit of blocking interleukin-6 activity with an anti-interleukin-6 receptor monoclonal antibody in rheumatoid arthritis: a randomized, doubleblind, placebo-controlled, dose-escalation trial. Arthritis Rheum 2002; 46: 3143-50.

[78] Wallenius V, Wallenius K, Ahren B, et al. Interleukin-6-deficient mice develop mature-onset obesity. Nat Med, 2002; 8: 75-79.

[79] Kubaszek A, Pihlajamaki J, Komarovski V, et al Promoter polymorphisms of the TNF-alpha (G-308A) and IL-6 (C-174G) genes predict the conversion from impaired glucose tolerance to type 2 diabetes: the Finnish Diabetes Prevention Study. Diabetes 2003; 52: $1872-6$

[80] Carey AL, Bruce CR, Sacchetti M, et al. Interleukin-6 and tumor necrosis factor-alpha are not increased in patients with type 2 diabetes: evidence that plasma IL-6 is related to fat mass and not insulin responsiveness. Diabetologia 2004; 47: 1029-37.

[81] Tillett WS, Francis T. Serological reactions in pneumonia with a non-protein somatic fraction of the pneumococcus. J Exp Med 1930; 52: 561-71.

[82] Emerging Risk Factors Collaboration, Kaptoge S, Di Angelantonio $\mathrm{E}$, Lowe $\mathrm{G}$, et al. C-reactive protein concentration and risk of coro- 
nary heart disease, stroke, and mortality: an individual participant meta-analysis. Lancet 2010; 375(9709): 132-40.

[83] Ridker PM. C-reactive protein and the prediction of cardiovascular events among those at intermediate risk: moving an inflammatory hypothesis toward consensus. J Am Coll Cardiol 2007; 49(21): 2129-38

[84] Liuzzo G, Biasucci LM, Gallimore JR, et al. The prognostic value of C-reactive protein and serum amyloid a protein in severe unstable angina. N Engl J Med 1994; 331: 417-24.

[85] Li J-J, Jiang H, Huang CX, et al. Elevated levels of plasma Creactive protein in patients with unstable angina: its relations with coronary stenosis and lipid profile. Angiology 2002; 53: 265-72.

[86] Li JJ, Li GS, Fang CH, et al. Activation of nuclear factor- $\kappa \mathrm{B}$ and correlation with elevated plasma $\mathrm{C}$-reactive protein in patients with unstable angina. Heart Lung Circ 2004; 13(2): 173-8.

[87] Liuzzo G, Biasucci LM, Rebuzzi AG, et al. Plasma protein acutephase response in unstable anigina is not induced by ischemic injury. Circulation 1996; 94: 2373-80.

[88] Ridker PM, Cushman M, Stampfer MJ, Tracy RP, Hennekens CH. Inflammation, aspirin, and the risk of cardiovascular disease in apparently healthy men. N Engl J Med 1997; 336: 973-9.

[89] Ridker PM, Hennekens CH, Buring JE, Rifai N. C-reactive protein and other markers of inflammation in the prediction of cardiovascular disease in women. N Engl J Med 2000; 342: 836-43.

[90] Kuller LH, Tracy RP, Shaten J, Meilahn EN. Relation of Creactive protein and coronary heart disease in the MRFIT nested casecontrol study. Multiple risk factor intervention trial. Am J Epidemiol 1996; 144: 537-47.

[91] Ridker PM, Glynn RJ, Hennekens CH. C-reactive protein adds to the predictive value of total and HDL cholesterol in determining risk of first myocardial infarction. Circulation 1998; 97: 2007-11.

[92] Ballou SP, Cleveland RP. Binding of human C-reactive protein to monocytes: analysis by flow cytometry. Clin Exp Immunol 1991; 84: 329-35.

[93] Pasceri V, Willerson JT, Yeh, ET. Direct proinflammatory effect of C-reactive protein on human endothelial cells. Circulation 2000; 102: 2165-8

[94] Venugopal SK, Devaraj S, Jialal I. C-reactive protein decreases prostacyclin release from human aortic endothelial cells. Circulation 2003; 108: 1676-8.

[95] Pasceri V, Cheng JS, Willerson JT, Yeh ET. Modulation of Creactive protein-mediated monocyte chemoattractant protein-1 induction in human endothelial cells by anti-atherosclerosis drugs. Circulation 2001; 103: 2531-4.

[96] Han KH, Hong KH, Park JH, et al. C-reactive protein promotes monocyte chemoattractant protein-1-mediated chemotaxis through upregulating CC chemokine receptor 2 expression in human monocytes. Circulation 2004; 109: 2566-71.

[97] Zwaka TP, Hombach V, Torzewski J. C-Reactive protein-mediated low density lipoprotein uptake by macrophages: implications for atherosclerosis. Circulation 2001; 103 : 1194-7.

[98] Torzewski J, Bowyer DE, Waltenberger J, Fitzsimmons C. Processes in atherogenesis: complement activation. Atherosclerosis 1997; $132: 131-8$

[99] Montero I, Orbe J, Varo N, et al. C-Reactive protein induces matrix metalloproteinase-1 and -10 in human endothelial cells: implications for clinical and subclinical atherosclerosis. J. Am. Coll. Cardiol 2006; 47: 1369-78.

[100] Devaraj S, Xu DY, Jialal I. C-reactive protein increases plasminogen activator inhibitor-1 expression and activity in human aortic endothelial cells: implications for the metabolic syndrome and atherothrombosis. Circulation 2003; 107: 398-404.

[101] Hirschfield GM, Gallimore JR, Kahan MC, et al. Transgenic human C-reactive protein is not proatherogenic in apolipoprotein Edeficient mice. Proc Natl Acad Sci USA 2005; 102: 8309-14.

[102] Paul A, Ko KW, Li L, Yechoor V, McCrory MA, Szalai AJ, Chan L. C-reactive protein accelerates the progression of atherosclerosis in apolipoprotein E-deficient mice. Circulation 2004; 109: 647-55.

[103] Schwedler SB, Amann K, Wernicke K, et al. Native C-reactive protein increases whereas modified $\mathrm{C}$-reactive protein reduces atherosclerosis in apolipoprotein E-knockout mice. Circulation 2005; 112: 1016-23

[104] Moore KW, O'Garra A, de Waal MR, Vieira P, Mosmann TR. Interleukin-10. Annu Rev Immunol 1993; 11: 165-90.

[105] Pretolani M. Interleukin-10: an anti-inflammatory cytokine with therapeutic potential. Clin Exp Allergy 1999; 29: 1164-71.
[106] Bogdan C, Paik J, Vodovotz Y, Nathan C. Contrasting mechanisms for suppression of macrophage cytokine release by transforming growth factor-beta and interleukin-10. J Biol Chem 1992; 267: 23301-8.

[107] Dinarello CA. The role of the interleukin-1-receptor antagonist in blocking inflammation mediated by interleukin-1. N Engl J Med 2000; 343: 732-4.

[108] Gabay C, Smith MF, Eidlen D, Arend WP. Interleukin 1 receptor antagonist (IL-1Ra) is an acute-phase protein. J Clin Invest 1997; 99: 2930-40.

[109] Wilhelmsen L, Svardsudd K, Korsan-Bengtsen K, Larsson B, Welin L, Tibblin G. Fibrinogen as a risk factor for stroke and myocardial infarction. N Engl J Med 1984; 311: 501-5.

[110] Kannel WB, Wolf PA, Castelli WP, D'Agostino RB. Fibrinogen and risk of cardiovascular disease: the Framingham Study. JAMA 1987; 258: 1183-6.

[111] Ma J, Hennekens CH, Ridker PM, Stampfer MJ. A prospective study of fibrinogen and risk of myocardial infarction in the Physicians' Health Study. J Am Coll Cardiol 1999; 33: 1347-52.

[112] Ridker PM, Stampfer MJ, Rifai N. Novel risk factors for systemic atherosclerosis: a comparison of C-reactive protein, fibrinogen, homocysteine, lipoprotein(a), and standard cholesterol screening as predictors of peripheral arterial disease. JAMA 2001; 285: 2481-5.

[113] Mora S, Rifai N, Buring JE, Ridker PM. Additive value of immunoassay-measured fibrinogen and high-sensitivity $\mathrm{C}$-reactive protein levels for predicting incident cardiovascular events. Circulation 2006; 114: 381-7

[114] Weuve J, Kang JH, Manson JE, Breteler MM, Ware JH, Grodstein F. Physical activity, including walking, and cognitive function in older women. JAMA 2004; 292: 1454-61.

[115] Abbott RD, White LR, Ross GW, Masaki KH, Curb JD, Petrovitch $\mathrm{H}$. Walking and dementia in physically capable elderly men. JAMA 2004; 292: 1447-53.

[116] Blair SN, Cheng Y, Holder JS. Is physical activity or physical fitness more important in defining health benefits? Med Sci Sports Exerc 2001; 33: S379-S399.

[117] Schantz P, Henriksson J, Jansson E. Adaptation of human skeletal muscle to endurance training of long duration. Clin Physiol, 1983 3: 141-51.

[118] Crampes F, Beauville M, Riviere D, Garrigues M. Effect of physical training in humans on the response of isolated fat cells to epinephrine. J Appl Physiol, 1986; 61: 25-9.

[119] van Loon LJ, Thomason-Hughes M, Constantin-Teodosiu D, et al. Inhibition of adipose tissue lipolysis increases intramuscular lipid and glycogen use in vivo in humans. Am J Physiol Endocrinol Metab 2005; 289(3): E482-93.

[120] Saltin B, Rowell LB. Functional adaptations to physical activity and inactivity. Federation Proc 1980; 39: 1506-13.

[121] Phillips SM, Green HJ, Tarnopolsky MA, Heigenhauser GF, Hill RE, Grant SM. Effects of training duration on substrate turnover and oxidation during exercise. J Appl Physiol, 1996; 81: 2182-91.

[122] Cesari M, Penninx BW, Pahor M, et al. Inflammatory markers and physical performance in older persons: the InCHIANTI study. J Gerontol A Biol Sci Med Sci 2004; 59: 242-8.

[123] Panagiotakos DB, Pitsavos C, Chrysohoou C, Kavouras S, Stefanadis $C$. The associations between leisure-time physical activity and inflammatory and coagulation markers related to cardiovascular disease: the ATTICA Study Prev Med 2005; 40: 432-7.

[124] Pitsavos C, Panagiotakos DB, Chrysohoou C, Kavouras S, Stefanadis $\mathrm{C}$. The associations between physical activity, inflammation, and coagulation markers, in people with metabolic syndrome: the ATTICA study. Eur J Cardiovasc Prev Rehabil 2005; 12: 151-8.

[125] Colbert LH, Visser M, Simonsick EM, et al. Physical activity, exercise, and inflammatory markers in older adults: findings from the health, aging and body composition study. J Am Geriatr Soc 2004; 52: 1098-104.

[126] Stauffer BL, Hoetzer GL, Smith DT, DeSouza CA. Plasma Creactive protein is not elevated in physically active postmenopausal women taking hormone replacement therapy. J Appl Physiol 2004; 96: 143-8.

[127] King DE, Carek P, Mainous III AG, Pearson WS. Inflammatory markers and exercise: differences related to exercise type. Med Sci Sports Exerc 2003; 35: 575-81.

[128] Manns PJ, Williams DP, Snow CM, Wander RC. Physical activity, body fat, and serum $\mathrm{C}$-reactive protein in postmenopausal women 
with and without hormone replacement. Am J Hum Biol 2003; 15: 91-100.

[129] Reuben DB, Judd-Hamilton L, Harris TB, Seeman TE. The associations between physical activity and inflammatory markers in high-functioning older persons: MacArthur studies of successful aging. J Am Geriatr Soc 2003; 51: 1125-30.

[130] Jankord R, Jemiolo B. Influence of physical activity on serum IL-6 and IL-10 levels in healthy older men. Med Sci Sports Exerc 2004; 36: $960-4$.

[131] Fischer CP, Berntsen A, Perstrup LB, Eskildsen P, Pedersen BK. Plasma levels of IL- 6 and CRP are associated with physical inactivity independent of obesity. Scand J Med Sci Sports 2007; 17: 5807.

[132] Tomaszewski M, Charchar FJ, Przybycin M, et al. Strikingly low circulating CRP concentrations in ultramarathon runners independent of markers of adiposity: how low can you go? Arterioscler Thromb Vasc Biol 2003; 23: 1640-4.

[133] Fredrikson GN, Hedblad B, Nilsson JA, Alm R, Berglund G, Nilsson J. Association between diet, lifestyle, metabolic cardiovascular risk factors, and plasma C-reactive protein levels. Metabolism 2004; 53: 1436-42.

[134] Verdaet D, Dendale P, De Bacquer D, Delanghe J, Block P, De Backer G. Association between leisure time physical activity and markers of chronic inflammation related to coronary heart disease. Atherosclerosis 2004; 176: 303-10.

[135] Rawson ES, Freedson PS, Osganian SK, Matthews CE, Reed G, Ockene IS. Body mass index, but not physical activity, is associated with C-reactive protein. Med Sci Sports Exerc 2003; 35: 11606.

[136] Goldhammer E, Ben-Sira D, Zaid G, et al. Paraoxonase activity following exercise-based cardiac rehabilitation program. J Cardiopulm Rehabil Prev 2007; 27(3): 151-4.

[137] Tisi PV, Hulse M, Chulakadabba A, Gosling P, Shearman CP. Exercise training for intermittent claudication: does it adversely affect biochemical markers of the exercise-induced inflammatory response? Eur J Vasc Endovasc Surg 1997: 14: 344-50.

[138] Gielen S, Adams V, Mobius-Winkler S, Linke A, et al. Antiinflammatory effects of exercise training in the skeletal muscle of patients with chronic heart failure. J Am Coll Cardiol 2003; 42: 8618.

[139] Kampus P, Kals J, Unt E, et al. Association between arterial elasticity, C-reactive protein and maximal oxygen consumption in well-trained cadets during three days extreme physical load: a pilot study. Physiol Meas 2008; 29(4): 429-37.

[140] Volpato S, Pahor M, Ferrucci L, et al. Relationship of alcohol intake with inflammatory markers and plasminogen activator inhibitor-1 in well-functioning older adults: the health, aging, and body composition study. Circulation 2004; 109: 607-12.

[141] Nicklas BJ, Ambrosius W, Messier SP, et al. Diet induced weight loss, exercise, and chronic inflammation in older, obese adults: a randomized controlled clinical trial. Am J Clin Nutr 2004; 79: 54451.

[142] Larsen AI, Aukrust P, Aarsland T, Dickstein K. Effect of aerobic exercise training on plasma levels of tumor necrosis factor- $\alpha$ in patients with heart failure. Am. J. Cardiol.2001; 88: 805-8.

[143] Steensberg A, van Hall G, Osada T, Sacchetti M, Saltin B, Klarlund PB. Production of interleukin-6 in contracting human skeletal muscles can account for the exercise-induced increase in plasma interleukin-6. J Physiol 2000; 529: 237-42.

[144] Gleeson M. Interleukins and exercise. J Physiol 2000; 529: 1.

[145] Keller C, Steensberg A, Pilegaard H, et al. Transcriptional activation of the IL-6 gene in human contracting skeletal muscle: influence of muscle glycogen content. FASEB J 2001; 15: 2748-50.

[146] Steensberg A, Febbraio MA, Osada T, et al. Interleukin-6 production in contracting human skeletal muscle is influenced by preexercise muscle glycogen content. J Physiol 2001; 537: 633-39.

[147] Carey AL, Febbraio MA. Interleukin-6 and insulin sensitivity: friend or foe? Diabetologia 2004; 47: 1135-42.

[148] Febbraio MA, Pedersen BK. Contraction-induced myokine production and release: is skeletal muscle an endocrine organ? Exerc Sport Sci Rev 2005; 33: 114-9.

[149] Pedersen BK, Fischer CP. Physiological roles of muscle-derived interleukin-6 in response to exercise. Curr Opin Clin Nutr Metab Care 2007; 10: 265-71.
[150] Suzuki K, Nakaji S, Yamada M, Totsuka M, Sato K, Sugawara K. Systemic inflammatory response to exhaustive exercise. Cytokine kinetics. Exerc Immunol Rev 2002; 8: 6-48.

[151] Starkie RL, Rolland J, Angus DJ, Anderson MJ, Febbraio MA. Circulating monocyes are not the source of elevations in plasma IL6 and TNF-alpha levels after prolonged running. Am J Physiol Cell Physiol 2001; 280: C769-74.

[152] Suzuki K, Yamada M, Kurakake S, et al. Circulating cytokines and hormones with immunosuppressive but neutrophilpriming potentials rise after endurance exercise in humans. Eur J Appl Physiol 2000; 81: 281-7.

[153] Fischer CP. Interleukin-6 in acute exercise and training: what is the biological relevance? Exercise Immunol Rev 2006; 12: 6-33.

[154] Margeli A, Skenderi K, Tsironi M, et al. Dramatic elevations of interleukin- 6 and acute-phase reactants in athletes participating in the ultradistance foot race spartathlon: severe systemic inflammation and lipid and lipoprotein changes in protracted exercise. J Clin Endocrinol Metab 2005; 90: 3914-8.

[155] Fischer CP, Hiscock NJ, Penkowa M, et al. Supplementation with vitamins $C$ and $E$ inhibits the release of interleukin- 6 from contracting human skeletal muscle. J Physiol 2004; 558: 633-45.

[156] Bruunsgaard H, Galbo H, Halkjaer-Kristensen J, Johansen TL, MacLean DA, Pedersen BK. Exercise-induced increase in interleukin-6 is related to muscle damage. J Physiol 1997; 499: 833-41.

[157] Hellsten Y, Frandsen U, Orthenblad N, Sjodin N, Richter EA. Xanthine oxidase in human skeletal muscle following eccentric exercise: a role of inflammation. J Physiol 1997; 498: 239-48.

[158] MacIntyre DL, Sorichter S, Mair J, Berg A, McKenzie DC. Markers of inflammation and myofibrillar proteins following eccentric exercise in humans. Eur J Appl Physiol 2001; 84: 180-6.

[159] Willoughby DS, McFarlin B, Bois C. Interleukin-6 expression after repeated bouts of eccentric exercise. Int J Sports Med 2003; 24: 15 21.

[160] Ostrowski K, Schjerling P, Pedersen BK. Physical activity and plasma interleukin-6 in humans: effect of intensity of exercise. Eur J Appl Physiol 2000; 83: 512-5.

[161] Bergfors M, Barnekow-Bergkvist M, Kalezic N, Lyskov E, Eriksson JW. Short-term effects of repetitive arm work and dynamic exercise on glucose metabolism and insulin sensitivity. Acta Physiol Scand 2005; 183: 345-56.

[162] Hirose L, Nosaka K, Newton M, et al. Changes in inflammatory mediators following eccentric exercise of the elbow flexors. Exerc Immunol Rev 2004; 10: 75-90.

[163] Nosaka K, Clarkson PM. Changes in indicators of inflammation after eccentric exercise of the elbow flexors. Med Sci Sports Exerc 1996; 28: 953-61.

[164] Nielsen HB, Secher N, Perdersen BK. Lymphocytes and NK cell activity during repeated bouts of maximal exercise. Am J Physiol Regul Integr Comp Physiol 1996; 271: R222-7.

[165] Jonsdottir IH, Schjerling P, Ostrowski K, Asp S, Richter EA, Pedersen BK. Muscle contractions induce interleukin-6 mRNA production in rat skeletal muscles. J Physiol 2000; 528: 157-63.

[166] Nehlsen-Canarella SL, Fagoaga OR, Nieman DC. Carbohydrate and the cytokine response to $2.5 \mathrm{~h}$ of running. J Appl Physiol 1997; 82: $1662-7$.

[167] Ullum H, Haahr PM, Diamant M, Palmo J, Halkjaer Kristensen J, Pedersen BK. Bicycle exercise enhances plasma IL-6 but does not change IL-1alpha, IL-1beta, IL-6, or TNF-alpha premRNA in BMNC. J Appl Physiol 1994; 77: 93-7.

[168] Moldoveanu AI, Shephard RJ, Shek PN. Exercise elevates plasma levels but not gene expression of IL-1 $\beta$, IL-6, TNF- $\alpha$ in blood mononuclear cells. J Appl Physiol 2000; 89: 1499-504.

[169] Starkie RL, Angus DJ, Rolland J, Hargreaves M, Febbraio M. Effect of prolonged submaximal exercise and carbohydrate ingestion on monocyte intracellular cytokine production in humans. $\mathrm{J}$ Physiol 2000; 528: 647-55.

[170] Starkie RL, Rolland J, Angus DJ, Anderson MJ, Febbraio MA. Circulating monocyes are not the source of elevations in plasma IL6 and TNF-alpha levels after prolonged running. Am J Physiol Cell Physiol 2001; 280: C769-74.

[171] Plomgaard P, Penkowa M, Pedersen BK. Fiber type specific expression of TNF-alpha, IL-6 and IL-18 in human skeletal muscles. Exerc Immunol Rev 2005; 11: 53-63.

[172] Willoughby DS, McFarlin B, Bois C. Interleukin-6 expression after repeated bouts of eccentric exercise. Int J Sports Med 2003; 24: 1521. 
[173] Steensberg A, Keller C, Starkie RL, Osada T, Febbraio MA, Pedersen BK. IL-6 and TNF-alpha expression in, release from, contracting human skeletal muscle. Am J Physiol Endocrinol Metab 2002; 283: E1272-8.

[174] Bartoccioni E, Michaelis D, Hohlfeld R. Constitutive and cytokineinduced production of interleukin- 6 by human myoblasts. Immunol Lett 1994; 42: 135-8.

[175] De Rossi M, Bernasconi P, Baggi F, de Waal MR, Mantegazza R. Cytokines and chemokines are both expressed by human myoblasts: possible relevance for the immune pathogenesis of muscle inflammation. Int Immunol 2000; 12: 1329-35.

[176] Yan SF, Tritto I, Pinsky D, Liao H, Huang J, Fuller G, et al. Induction of interleukin 6 (IL-6) by hypoxia in vascular cells. Central role of the binding site for nuclear factor-IL-6. J Biol Chem 1995; 270: 11463-71.

[177] Klouche M, Bhakdi S, Hemmes M, Rose-John S. Novel path to activation of vascular smooth muscle cells: up-regulation of gp130 creates an autocrine activation loop by IL-6 and its soluble receptor. J Immunol 1999; 163: 4583-9.

[178] Langberg H, Olesen J, Gemmer C, Kjaer M. IL-6 production in various types of tissues as measured by microdialysis in response to exercise in humans. J Physiol 2002; 539P.

[179] Keller C, Steensberg A, Hansen AK, Fischer CP, Plomgaard P, Pedersen BK. The effect of exercise, training, glycogen availability on IL-6 receptor expression in human skeletal muscle. J Appl Physiol 2005; 99: 2075-9

[180] Malm C, Nyberg P, Engstrom M, Sjodin B, Lenkei R, Ekblom B. Immunological changes in human skeletal muscle and blood after eccentric exercise and multiple biopsies. J Physiol 2000; 529: 24362.

[181] Hiscock N, Chan MH, Bisucci T, Darby IA, Febbraio MA. Skeletal myocytes are a source of interleukin-6 mRNA expression and protein release during contraction: evidence of fiber type specificity. FASEB J 2004; 18: 992-4

[182] Penkowa M, Keller C, Keller P, Jauffred S, Pedersen BK. Immunohistochemical detection of interleukin-6 in human skeletal muscle fibers following exercise. FASEB J 2003; 17: 2166-8.

[183] Langberg H, Olesen JL, Gemmer C, Kjaer M. Substantial elevation of interleukin-6 concentration in peritendinous tissue, in contrast to muscle, following prolonged exercise in humans. J Physiol 2002; 542: 985-990.

[184] Rosendal L, Sogaard K, Kjaer M, Sjogaard G, Langberg H, Kristiansen J. Increase in interstitial interleukin-6 of human skeletal muscle with repetitive low-force exercise. J Appl Physiol 2005; 98: 477-81.

[185] Nybo L, Nielsen B, Pedersen BK, Moller K, Secher NH. Interleukin-6 release from the human brain during prolonged exercise. J Physiol 2002; 542: 991-5.

[186] Ostrowski K, Rohde T, Zacho M, Asp S, Pedersen BK. Evidence that IL-6 is produced in skeletal muscle during prolonged running. J Physiol 1998; 508: 949-53.

[187] Ullum H, Haahr PM, Diamant M, Palmo J, Halkjaer Kristensen J, Pedersen BK. Bicycle exercise enhances plasma IL-6 but does not change IL-1alpha, IL-1beta, IL-6, or TNF-alpha pre-mRNA in BMNC. J Appl Physiol 1994; 77: 93-7.

[188] Vassilakopoulos T, Karatza MH, Katsaounou P, Kollintza A, Zakynthinos S, Roussos C. Antioxidants attenuate the plasma cytokine response to exercise in humans. J Appl Physiol 2003; 94: 1025-32.

[189] Sopasakis VR, Sandqvist M, Gustafson B, et al. High local concentrations and effects on differentiation implicate interleukin-6 as a paracrine regulator. Obes Res 2004; 12: 454-60

[190] Keller C, Keller P, Marshall-Gradisnik SM, Pedersen BK. IL-6 gene expression in human adipose tissue in response to exercise: effect of carbohydrate ingestion. J Physiol 2003; 550: 927-31.

[191] Lyngso D, Simonsen L, Bulow J. Interleukin-6 production in human subcutaneous abdominal adipose tissue: the effect of exercise. J Physiol 2002; 543: 373-8.

[192] Akira S, Taga T, Kishimoto T. Interleukin-6 in biology and medicine. Adv Immunol 1993; 54: 1-78.

[193] Febbraio MA, Pedersen BK. Muscle-derived interleukin-6: mechanisms for activation and possible biological roles. FASEB J 2002; 16: 1335-47.

[194] Keller C, Hellsten Y, Steensberg A, Pedersen BK. Differential regulation of IL-6 and TNF-alpha via calcineurin in human skeletal muscle cells. Cytokine 2006; 36: 141-7.
[195] Lancaster GI, Jentjens RL, Moseley L, Jeukendrup AE, Gleeson M. Effect of pre-exercise carbohydrate ingestion on plasma cytokine, stress hormone, neutrophil degranulation responses to continuous, high-intensity exercise. Int J Sport Nutr Exerc Metab 2003; 13: 436-53.

[196] Van Hall G, Steensberg A, Sacchetti M, et al. Interleukin-6 stimulates lipolysis and fat oxidation in humans. J Clin Endocrinol Metab 2003; 88: 3005-10.

[197] Bruce CR, Dyck DJ. Cytokine regulation of skeletal muscle fatty acid metabolism: effect of interleukin-6 and tumor necrosis factorAm J Physiol Endocrinol Metab 2004; 287: E616-21.

[198] Li TL, Wu CL, Gleeson M, Williams C. The effects of preexercise high carbohydrate meals with different glycemic indices on blood leukocyte redistribution, IL-6, hormonal responses during a subsequent prolonged exercise. Int J Sport Nutr Exerc Metab 2004; 14: 647-56.

[199] Li TL, Gleeson M. The effects of carbohydrate supplementation during the second of two prolonged cycling bouts on immunoendocrine responses. Eur J Appl Physiol 2005; 95: 391-9.

[200] Nieman DC, Davis JM, Henson DA, et al. Muscle cytokine mRNA changes after $2.5 \mathrm{~h}$ of cycling: influence of carbohydrate. Med Sci Sports Exerc 2005; 37: 1283-90

[201] Febbraio MA, Steensberg A, Keller C, et al. Glucose ingestion attenuates interleukin-6 release from contracting skeletal muscle in humans. J Physiol 2003; 549: 607-12.

[202] Nieman DC, Nehlsen-Canarella SL, Fagoaga OR, et al. Influence of mode and carbohydrate on the cytokine response to heavy exertion. Med Sci Sports Exerc 1998; 30: 671-8.

[203] Nieman DC, Davis JM, Henson DA, et al. Carbohydrate ingestion influences skeletal muscle cytokine mRNA and plasma cytokine levels after a 3-h run. J Appl Physiol 2003; 94: 1917-25.

[204] Nieman DC, Henson DA, Smith LL, et al. Cytokine changes after a marathon race. J Appl Physiol 2001; 91: 109-14.

[205] Suzuki K, Nakaji S, Yamada M, et al. Impact of a competitive marathon race on systemic cytokine and neutrophil responses. Med Sci Sports Exerc 2003; 35: 348-55.

[206] Chan MH, Carey AL, Watt MJ, Febbraio MA. Cytokine gene expression in human skeletal muscle during concentric contraction evidence that IL-8, like IL-6, is influenced by glycogen availability. Am J Physiol Regul Integr Comp Physiol 2004; 287: R322-7.

[207] Henson DA, Nieman DC, Nehlsen-Cannarella SL, et al. Influence of carbohydrate on cytokine and phagocytic responses to $2 \mathrm{~h}$ of rowing. Med Sci Sports Exerc 2000; 32: 1384-9.

[208] Mucci P, Durand F, Lebel B, Bousquet J, Prefaut C. Interleukins 1beta, -8 , histamine increases in highly trained, exercising athletes. Med Sci Sports Exerc 2000; 32: 1094-100.

[209] Akerstrom TC, Steensberg A, Keller P, Keller C, Penkowa M, Pedersen BK. Exercise induces interleukin-8 expression in human skeletal muscle. J Physiol 2005; 563: 507-16.

[210] De Rossi M, Bernasconi P, Baggi F, de Waal MR, Mantegazza R. Cytokines and chemokines are both expressed by human myoblasts: possible relevance for the immune pathogenesis of muscle inflammation.Int Immunol 2000; 12: 1329-35.

[211] Bek EL, McMillen MA, Scott P, Angus LD, Shaftan GW. The effect of diabetes on endothelin, interleukin-8 and vascular endothelial growth factor-mediated angiogenesis in rats. Clin Sci 2002; 103 Suppl 48: 424S-9S.

[212] Koch AE, Polverini PJ, Kunkel SL, et al. Interleukin-8 as a macrophage-derived mediator of angiogenesis. Science 1992; 258: 1798801.

[213] Norrby K. Interleukin-8 and de novo mammalian angiogenesis Cell Prolif 1996; 29: 315-23.

[214] Bamford RN, Grant AJ, Burton JD, et al. The interleukin (IL) 2 receptor beta chain is shared by IL-2 and a cytokine, provisionally designated IL-T, that stimulates T-cell proliferation and the induction of lymphokine-activated killer cells. Proc Natl Acad Sci USA 1994; 91: 4940-4.

[215] Grabstein KH, Eisenman J, Shanebeck K, et al. Cloning of a T cell growth factor that interacts with the beta chain of the interleukin-2 receptor. Science 1994; 264: 965-8.

[216] Ostrowski K, Hermann C, Bangash A, Schjerling P, Nielsen JN, Pedersen BK. A trauma-like elevation of plasma cytokines in humans in response to treadmill running. J Physiol 1998; 513: 889-94.

[217] Riechman SE, Balasekaran G, Roth SM, Ferrell RE. Association of interleukin-15 protein and interleukin-15 receptor genetic variation 
with resistance exercise training responses. J Appl Physiol 2004; 97: 2214-9.

[218] Nielsen AR, Hojman P, Erikstrup C, Fischer CP, Plomgaard P, Mounier R. Association between interleukin-15 and obesity: interleukin-15 as a potential regulator of fat mass. J Clin Endocrinol Metab 2008; 93(11): 4486-93.

[219] Argiles JM, Lopez-Soriano J, Almendro V, Busquets S, LopezSoriano FJ. Cross-talk between skeletal muscle and adipose tissue: a link with obesity? Med Res Rev 2005; 25: 49-65.

[220] Furmanczyk PS, Quinn LS. Interleukin-15 increases myosin accretion in human skeletal myogenic cultures. Cell Biol Int 2003; 27 : 845-51.

[221] Quinn LS, Haugk KL, Damon SE. Interleukin-15 stimulates C2 skeletal myoblast differentiation. Biochem Biophys Res Commun 1997; 239: 6-10.

[222] Quinn LS, Anderson BG, Drivdahl RH, Alvarez B, Argiles JM. Overexpression of interleukin-15 induces skeletal muscle hypertrophy in vitro: implications for treatment of muscle wasting disorders. Exp Cell Res 2002; 280: 55-63.

[223] Carbo N, Lopez-Soriano J, Costelli P, et al. Interleukin-15 mediates reciprocal regulation of adipose and muscle mass: a potential role in body weight control. Biochim Biophys Acta 2001; 1526: 17-24.

[224] Delaigle AM, Jonas JC, Bauche IB, Cornu O, Brichard SM. Induction of adiponectin in skeletal muscle by inflammatory cytokines: in vivo and in vitro studies. Endocrinology 2004; 145: 5589-97.

[225] Dillard CJ, Litov RE, Savin WM, Dumelin EE, Tappel AL. Effects of exercise, vitamin $\mathrm{E}$, and ozone on pulmonary function and lipid peroxidation. J Appl Physiol 1978; 45: 927-32.

[226] Lawler JM, Powers SK, Van Dijk H, Visser T, Kordus MJ, Ji LL. Metabolic and antioxidant enzyme activities in the diaphragm: effects of acute exercise. Respir Physiol 1994; 96: 139-49.

[227] Hudson MB, Hosick PA, McCaulley GO, et al. The effect of resistance exercise on humoral markers of oxidative stress. Med Sci Sports Exerc 2008; 40: 542-8.

[228] McAnulty SR, Hosick PA, McAnulty LS, et al. Effect of pharmacological lowering of plasma urate on exercise-induced oxidative stress. Appl Physiol Nutr Metab 2007; 32: 1148-55.

[229] Quindry JC, McAnulty SR, Hudson MB, et al. Oral quercetin supplementation and blood oxidative capacity in response to ultramarathon competition. Int J Sport Nutr Exerc Metab 2008; 18: 60116

[230] McAnulty SR, McAnulty LS, Nieman DC, et al. Chronic quercetin ingestion and exercise-induced oxidative damage and inflammation. Appl Physiol Nutr Metab 2008; 33: 254-62.

[231] Powers SK, Jackson MJ. Exercise-induced oxidative stress: cellular mechanisms and impact on muscle force production. Physiol Rev 2008; 88: 1243-76.

[232] Nikolaidis MG, Jamurtas AZ. Blood as a reactive species generator and redox status regulator during exercise. Arch Biochem Biophys 2009; 490: 77-84.

[233] Reid MB. Redox modulation of skeletal muscle contraction: what we know and what we don't. J Appl Physiol 2001; 90: 724-31.

[234] Supinski GS, Callahan LA. Free radical-mediated skeletal muscle dysfunction in inflammatory conditions. J Appl Physiol 2007; 102: 2056-63.

[235] Reid MB, Khawli FA, Moody MR. Reactive oxygen in skeletal muscle. III. Contractility of unfatigued muscle. J Appl Physiol 1993; 75: 1081-7.

[236] Reid MB, Moody MR. Dimethyl sulfoxide depresses skeletal muscle contractility. J Appl Physiol 1994; 76: 2186-90.

[237] Coombes JS, Powers SK, Rowell B, et al. Effects of vitamin E and alpha-lipoic acid on skeletal muscle contractile properties. J Appl Physiol 2001; 90: 1424-30.

[238] Ji LL. Antioxidants and oxidative stress in exercise. Proc Soc Exp Biol Med 1999; 222: 283-92.

[239] Brennan ML, Penn MS, Van Lente F, et al. Prognostic value of myeloperoxidase in patients with chest pain. N Engl J Med 2003; 349: 1595-604.

[240] Patrono C, FitzGerald GA. Isoprostanes: potential markers of oxidant stress in atherothrombotic disease. Arterioscler Thromb Vasc Biol 1997; 17: 2309-15.

[241] Wetzstein CJ, Shern-Brewer RA, Santanam N, Green NR, WhiteWelkley JE, Parthasarathy S. Does acute exercise affect the susceptibility of low density lipoprotein to oxidation? Free Radical Biol Med 1998; 24: 679-82.
[242] Van Berkel TJ, De Rijke YB, Kruijt JK. Different fate in vivo of oxidatively modified low density lipoprotein and acetylated low density lipoprotein in rats. Recognition by various scavenger receptors on Kupffer and endothelial liver cells. J Biol Chem 1991; 266: 2282-9.

[243] Meilhac O, Ramachandran S, Chiang K, Santanam N, Parthasarathy $\mathrm{S}$. Role of arterial wall antioxidant defense in beneficial effects of exercise on atherosclerosis in mice. Arterioscler Thromb Vasc Biol 2001; 21: 1681-8.

[244] Galassetti PR, Nemet D, Pescatello A, Rose-Gottron C, Larson J, Cooper DM. Exercise, caloric restriction, and systemic oxidative stress. J Invest Med 2006; 54: 67-75.

[245] Richter B, Niessner A, Penka M , et al. Endurance training reduces circulating asymmetric dimethylarginine and myeloperoxidase levels in persons at risk of coronary events. Thromb. Haemostasis 2005; 94: 1306-11.

[246] Hansson GK. Inflammation, atherosclerosis, and coronary artery disease. N Engl J Med 2005; 352(16): 1685-95.

[247] Lusis AJ. Atherosclerosis. Nature 2000; 407(6801): 233-41.

[248] Willerson JT, Ridker PM. Inflammation as a cardiovascular risk factor. Circulation 2004 Jun 1; 109(21 Suppl 1): II2-10

[249] Kleemann R, Zadelaar S, Kooistra T. Cytokines and atherosclerosis: a comprehensive review of studies in mice. Cardiovascular research 2008; 79(3): 360-76.

[250] Saadeddin SM, Habbab MA, Ferns GA. Markers of inflammation and coronary artery disease. Med Sci Monit 2002; 8(1): RA5RA12.

[251] Pearson JD. Normal endothelial cell function. Lupus 2000; 9(3): 183-8.

[252] Constans J, Conri C. Circulating markers of endothelial function in cardiovascular disease. Clin Chim Acta 2006; 368(1-2): 33-47.

[253] Mombouli JV, Vanhoutte PM. Endothelial dysfunction: from physiology to therapy. J Mol Cell Cardiol 1999; 31(1): 61-74.

[254] Corti R, Hutter R, Badimon JJ, Fuster V. Evolving concepts in the triad of atherosclerosis, inflammation and thrombosis. J Thromb Thrombolysis 2004; 17(1): 35-44.

[255] Lewis TV, Dart AM, Chin-Dusting JP, Kingwell BA. Exercise training increases basal nitric oxide production from the forearm in hypercholesterolemic patients. Arterioscler Thromb Vasc Biol 1999; 19(11): 2782-7.

[256] Higashi Y, Sasaki S, Kurisu S, et al. Regular aerobic exercise augments endothelium-dependent vascular relaxation in normotensive as well as hypertensive subjects: role of endothelium-derived nitric oxide. Circulation 1999; 100(11): 1194-202.

[257] Lavrencic A, Salobir BG, Keber I. Physical training improves flowmediated dilation in patients with the polymetabolic syndrome. Arterioscler Thromb Vasc Biol 2000; 20(2): 551-5.

[258] Maiorana A, O'Driscoll G, Cheetham C, et al. The effect of combined aerobic and resistance exercise training on vascular function in type 2 diabetes. J Am Coll Cardiol 2001; 38(3): 860-6.

[259] Hambrecht R, Wolf A, Gielen S, et al. Effect of exercise on coronary endothelial function in patients with coronary artery disease. N Engl J Med 2000; 342(7): 454-60.

[260] Gokce N, Vita JA, Bader DS, et al. Effect of exercise on upper and lower extremity endothelial function in patients with coronary artery disease. Am J Cardiol 2002; 90(2): 124-7.

[261] Gielen S, Erbs S, Linke A, Mobius-Winkler S, Schuler G, Hambrecht R. Home-based versus hospital-based exercise programs in patients with coronary artery disease: effects on coronary vasomotion. Am Heart J 2003; 145(1): E3

[262] Sessa WC, Pritchard K, Seyedi N, Wang J, Hintze TH. Chronic exercise in dogs increases coronary vascular nitric oxide production and endothelial cell nitric oxide synthase gene expression. Circ Res 1994; 74(2): 349-53.

[263] Woodman CR, Muller JM, Laughlin MH, Price EM. Induction of nitric oxide synthase mRNA in coronary resistance arteries isolated from exercise-trained pigs. Am J Physiol 1997; 273(6 Pt 2): H2575-9.

[264] Davis ME, Cai H, Drummond GR, Harrison DG. Shear stress regulates endothelial nitric oxide synthase expression through c-Src by divergent signaling pathways. Circ Res 2001; 89(11): 1073-80.

[265] Ranjan V, Xiao Z, Diamond SL. Constitutive NOS expression in cultured endothelial cells is elevated by fluid shear stress. Am J Physiol 1995; 269(2 Pt 2): H550-5. 
[266] Venema RC, Nishida K, Alexander RW, Harrison DG, Murphy TJ. Organization of the bovine gene encoding the endothelial nitric oxide synthase. Biochim Biophys Acta 1994; 1218(3): 413-20.

[267] Hambrecht R, Adams V, Erbs S, et al. Regular physical activity improves endothelial function in patients with coronary artery disease by increasing phosphorylation of endothelial nitric oxide synthase. Circulation 2003; 107(25): 3152-8.

[268] Fukai T, Siegfried MR, Ushio-Fukai M, Cheng Y, Kojda G, Harrison DG. Regulation of the vascular extracellular superoxide dismutase by nitric oxide and exercise training. J Clin Invest 2000; 105(11): 1631-9.

[269] Ennezat PV, Malendowicz SL, Testa M, et al. Physical training in patients with chronic heart failure enhances the expression of genes encoding antioxidative enzymes. J Am Coll Cardiol 2001; 38(1): 194-8.

[270] Dimmeler S, Haendeler J, Rippmann V, Nehls M, Zeiher AM. Shear stress inhibits apoptosis of human endothelial cells. FEBS Lett 1996; 399(1-2): 71-4.

[271] Inoue N, Ramasamy S, Fukai T, Nerem RM, Harrison DG. Shear stress modulates expression of $\mathrm{Cu} / \mathrm{Zn}$ superoxide dismutase in human aortic endothelial cells. Circ Res 1996; 79(1): 32-7.

[272] Dimmeler S, Hermann C, Galle J, Zeiher AM. Upregulation of superoxide dismutase and nitric oxide synthase mediates the apoptosis-suppressive effects of shear stress on endothelial cells. Arterioscler Thromb Vasc Biol 1999; 19(3): 656-64.

[273] Takeshita S, Inoue N, Rikitake Y, Kawashima S, Yokoyama M. Mechanical stress modulates glutathione peroxidase expression in cultured bovine aortic endothelial cells. Ann N Y Acad Sci 2000; 902: 298-301.

[274] Rush JW, Turk JR, Laughlin MH. Exercise training regulates SOD1 and oxidative stress in porcine aortic endothelium.AmJ Physiol Heart Circ Physiol 2003; 284(4): H1378-87.

[275] Berliner JA, Navab M, Fogelman AM, et al. Atherosclerosis: basic mechanisms. Oxidation, inflammation, and genetics. Circulation 1995; 91(9): 2488-96.

[276] Shern-Brewer R, Santanam N, Wetzstein C, White-Welkley J, Parthasarathy S. Exercise and cardiovascular disease: a new perspective. Arterioscler Thromb Vasc Biol 1998; 18(7): 1181-7.

[277] Green DJ, Maiorana A, O'Driscoll G, Taylor R. Effect of exercise training on endothelium-derived nitric oxide function in humans. $\mathrm{J}$ Physiol 2004; 561(Pt 1): 1-25.

[278] Maiorana A, O'Driscoll G, Taylor R, Green D. Exercise and the nitric oxide vasodilator system. Sports Med (Auck, NZ) 2003; 33(14): 1013-35

[279] Tjonna AE, Lee SJ, Rognmo O, et al. Aerobic interval training versus continuous moderate exercise as a treatment for the metabolic syndrome: a pilot study. Circulation 2008; 118(4): 346-54.

[280] Wisloff U, Stoylen A, Loennechen JP, et al. Superior cardiovascular effect of aerobic interval training versus moderate continuous training in heart failure patients: a randomized study. Circulation 2007; 115(24): 3086-94.

[281] Bevilacqua MP, Nelson RM, Mannori G, Cecconi O. Endothelialleukocyte adhesion molecules in human disease. Annu Rev Med 1994; 45: 361-78

[282] Frenette PS, Wagner DD. Adhesion molecules-Part 1. NEngl J Med 1996; 334(23): 1526-9

[283] Wegge JK, Roberts CK, Ngo TH, Barnard RJ. Effect of diet and exercise intervention on inflammatory and adhesion molecules in postmenopausal women on hormone replacement therapy and at risk for coronary artery disease. Metabolism 2004; 53(3): 377-81

[284] Adamopoulos S, Parissis J, Kroupis C, et al. Physical training reduces peripheral markers of inflammation in patients with chronic heart failure. Eur Heart J 2001; 22(9): 791-7.

[285] Bjornstad HH, Bruvik J, Bjornstad AB, Hjellestad BL, Damas JK, Aukrust P. Exercise training decreases plasma levels of soluble CD40 ligand and P-selectin in patients with chronic heart failure. Eur J Cardiovasc Prev Rehabil 2008; 15(1): 43-8.

[286] Yang AL, Chen HI. Chronic exercise reduces adhesion molecules/iNOS expression and partially reverses vascular responsiveness in hypercholesterolemic rabbit aortae. Atherosclerosis 2003; 169(1): 11-7.

[287] Yang AL, Jen CJ, Chen HI. Effects of high-cholesterol diet and parallel exercise training on the vascular function of rabbit aortas: a time course study. J Appl Physiol 2003; 95(3): 1194-200.

[288] Ando J, Tsuboi H, Korenaga R, et al. Shear stress inhibits adhesion of cultured mouse endothelial cells to lymphocytes by downregu- lating VCAM-1 expression. Am J Physiol 1994; 267(3 Pt 1): C67987.

[289] Goldhammer E, Tanchilevitch A, Maor I, Beniamini Y, Rosenschein U, Sagiv M. Exercise training modulates cytokines activity in coronary heart disease patients. Int J Cardiol 2005; 100(1): 93-9.

[290] Walther C, Möbius-Winkler S, Linke A, et al. Regular exercise training compared with percutaneous intervention leads to a reduction of inflammatory markers and cardiovascular events in patients with coronary artery disease. Eur J Cardiovasc Prev Rehabil 2008; 15(1): 107-12.

[291] Kim YJ, Shin YO, Bae JS, et al. Beneficial effects of cardiac rehabilitation and exercise after percutaneous coronary intervention on hsCRP and inflammatory cytokines in CAD patients. Pflugers Arch 2008; 455(6): 1081-8

[292] Balen S, Vukelić-Damijani N, Persić V, et al. Anti-inflammatory effects of exercise training in the early period after myocardial infarction. Coll Antropol 2008; 32(1): 285-91.

[293] Niessner A, Richter B, Penka M, et al. Endurance training reduces circulating inflammatory markers in persons at risk of coronary events: impact on plaque stabilization? Atherosclerosis 2006 186(1): 160-5.

[294] Smith JK, Dykes R, Douglas JE, Krishnaswamy G, Berk S. Longterm exercise and atherogenic activity of blood mononuclear cells in persons at risk of developing ischemic heart disease. JAMA 1999; 281(18): 1722-7.

[295] Milani RV, Lavie CJ, Mehra MR. Reduction in C-reactive protein through cardiac rehabilitation and exercise training. J Am Coll Cardiol 2004; 43(6): 1056-61.

[296] Milani RV, Lavie CJ. Prevalence and profile of metabolic syndrome in patients following acute coronary events and effects of therapeutic lifestyle change with cardiac rehabilitation. Am J Cardiol 2003; 92(1): 50-4

[297] Caulin-Glaser T, Falko J, Hindman L, La Londe M, Snow R. Cardiac rehabilitation is associated with an improvement in C-reactive protein levels in both men and women with cardiovascular disease. J Cardiopulm Rehabil 2005; 25(6): 332-338.

[298] Pluss CE, Karlsson MR, Wallen NH, Billing E, Held C. Effects of an expanded cardiac rehabilitation programme in patients treated for an acute myocardial infarction or a coronary artery by-pass graft operation. Clin Rehabil 2008; 22(4): 306-18

[299] Sixt S, Rastan A, Desch S, et al. Exercise training but not rosiglitazone improves endothelial function in prediabetic patients with coronary disease. Eur J Cardiovasc Prev Rehabil 2008; 15(4): 4738 .

[300] Hansen D, Dendale P, Berger J, et al. Importance of exercise training session duration in the rehabilitation of coronary artery disease patients. Eur J Cardiovasc Prev Rehabil 2008; 15(4): 453-9.

[301] Shin YO, Bae JS, Lee JB, et al. Effect of cardiac rehabilitation and statin treatment on anti-HSP antibody titers in patients with coronary artery disease after percutaneous coronary intervention. Int Heart J 2006; 47(5): 671-82

[302] Lavie CJ, Milani RV. Adverse psychological and coronary risk profiles in young patients with coronary artery disease and benefits of formal cardiac rehabilitation. Arch Intern Med 2006; 166(17) 1878-83.

[303] Huffman KM, Samsa GP, Slentz CA, et al. Response of highsensitivity C-reactive protein to exercise training in an at-risk population. Am Heart J 2006; 152(4): 793-800.

[304] Kasapis C, Thompson PD. The effects of physical activity on serum C-reactive protein and inflammatory markers: a systematic review. J Am Coll Cardiol 2005; 45(10): 1563-9.

[305] Lemieux I, Pascot A, Prud'homme D, et al. Elevated C-reactive protein: another component of the atherothrombotic profile of abdominal obesity. Arterioscler Thromb Vasc Biol 2001; 21(6): 9617.

[306] McLaughlin T, Abbasi F, Lamendola C, et al. Differentiation between obesity and insulin resistance in the association with Creactive protein. Circulation 2002; 106(23): 2908-12.

[307] Ford ES. Does exercise reduce inflammation? Physical activity and C-reactive protein among U.S. adults. Epidemiology 2002; 13: 561-8.

[308] Yudkin JS, Stehouwer CD, Emeis JJ, Coppack SW. C-reactive protein in healthy subjects: associations with obesity, insulin resistance, and endothelial dysfunction: a potential role for cytokines originating from adipose tissue? Arterioscler Thromb Vasc Biol 1999; 19(4): 972-8. 
[309] King DE, Carek P, Mainous III AG, Pearson WS. Inflammatory markers and exercise: differences related to exercise type. Med Sci Sports Exercise 2003; 35: 575-81.

[310] Abramson JL, Vaccarino V. Relationship between physical activity and inflammation among apparently healthy middle-aged and older US adults. Arch Intern Med 2002; 162: 1286-92.

[311] Albert MA, Glynn RJ, Ridker PM. Effect of physical activity on serum C-reactive protein. Am J Cardiol 2004; 93: 221-5.

[312] Isasi CR, Deckelbaum RJ, Tracy RP, Starc TJ, Berglund L, Shea S. Physical fitness and C-reactive protein level in children and young adults: the Columbia University BioMarkers Study. Pediatrics 2003; 111: 332-8.

[313] Verdaet D, Dendale P, De Bacquer D, Delanghe J, Block P, De Backer G. Association between leisure time physical activity and markers of chronic inflammation related to coronary heart disease. Atherosclerosis 2004; 176: 303-10

[314] Rawson ES, Freedson PS, Osganian SK, Matthews CE, Reed G, Ockene IS. Body mass index, but not physical activity, is associated with C-reactive protein. Med Sci Sports Exercise 2003; 35: 1160-6

[315] Kelley GA, Kelley KS. Effects of aerobic exercise on C-reactive protein, body composition, and maximum oxygen consumption in adults: a meta-analysis of randomized controlled trials. Metab Clin Exp 2006; 55: 1500-7.

[316] Kohut ML, McCann DA, Russell DW, et al. Aerobic exercise, but not flexibility/resistance exercise, reduces serum IL-18, CRP, and IL-6 independent of $\beta$-blockers, BMI, and psychosocial factors in older adults. Brain Behav Immunol 2006; 20: 201-9.

[317] Plaisance EP, Grandjean PW. Physical activity and high-sensitivity C-reactive protein. Sports Med 2006; 36: 443-58.

[318] Mattusch F, Dufaux B, Heine O, Mertens I, Rost R. Reduction of the plasma concentration of $\mathrm{C}$-reactive protein following nine months of endurance training. Int. J Sports Med 2000; 21: 21-4.

[319] Selvin E, Paynter NP, Erlinger TP. The effect of weight loss on Creactive protein: a systematic review. Arch Intern Med 2007; 167: 31-9.

[320] Stewart LK, Flynn MG, Campbell WW, et al. The influence of exercise training on inflammatory cytokines and C-reactive protein. Med Sci Sports Exerc 2007; 39: 1714-9.
[321] de Salles BF, Simão R, Fleck SJ, Dias I, Kraemer-Aguiar LG, Bouskela E. Effects of resistance training on cytokines. Int J Sports Med 2010; 31: 441-50.

[322] Rauramaa R, Halonen P, Väisänen SB, Lakka TA, SchmidtTrucksäss A, Berg A. Effects of Aerobic Physical Exercise on Inflammation and Atherosclerosis in Men: The DNASCO Study. Ann Intern Med 2004; 140(12): 1007-14.

[323] Geffken DF, Cushman M, Burke GL, Polak JF, Sakkinen PA, Tracy RP. Association between physical activity and markers of inflammation in a healthy elderly population. Am J Epidemiol 2001; 153: $242-50$.

[324] Pischon T, Hankinson SE, Hotamisligil GS, Rifai N, Rimm EB. Leisure-time physical activity and reduced plasma levels of obesity-related inflammatory markers. Obes Res 2003; 11: 1055-64.

[325] Reuben DB, Judd-Hamilton L, Harris TB, Seeman TE; MacArthur Studies of Successful Aging. The associations between physical activity and inflammatory markers in high-functioning older persons: MacArthur Studies of Successful Aging. J Am Geriatr Soc 2003; 51: $1125-30$.

[326] Harvnder SD, Bhardwaj R, Sajja V, et al. Effect of Intensive Lifestyle Changes on Endothelial Function and on Inflammatory Markers of Atherosclerosis. Am J Cardiol 2010; 105: 362-7.

[327] Lawler JM, Kwak HB, Song W, Parker JL. Exercise training reverses downregulation of HSP70 and antioxidant enzymes in porcine skeletal muscle after chronic coronary artery occlusion. Am J Physiol Regul Integr Comp Physiol 2006; 291(6): R1756-63.

[328] Richter B, Niessner A, Penka M, et al. Endurance training reduces circulating asymmetric dimethylarginine and myeloperoxidase levels in persons at risk of coronary events. Thromb Haemost 2005; 94(6): 1306-11.

[329] Keller C, Keller P, Giralt M, Hidalgo J, Pedersen BK. Exercise normalizes overexpression of TNF- $\alpha$ in knockout mice. Biochem. Biophys. Res. Commun 2004; 321: 179-82.

[330] Ferrier KE, Nestel P, Taylor A, Drew BG, Kingwell BA. Diet but not aerobic exercise training reduces skeletal muscle TNF- $\alpha$ in overweight humans. Diabetologia 2004; 47: 630-7. 